\title{
Descemet Membrane Endothelial Keratoplasty and Bowman Layer Transplantation: An Anatomic Review and Historical Survey
}

\author{
Jack Parker ${ }^{a, b}$ Philip Dockery ${ }^{a, c}$ Ana Preda-Naumescu ${ }^{d}$ Martine Jager $^{\mathrm{e}}$ \\ Korine van Dijk, g Isabel Dapena ${ }^{f, g}$ Gerrit Melles ${ }^{a, f, g}$

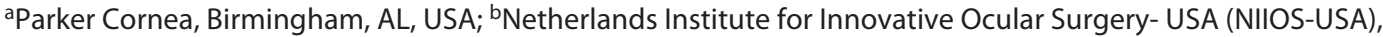 \\ San Diego, CA, USA; 'Wills Eye Hospital, Philadelphia, PA, USA; 'University of Alabama at Birmingham School of \\ Medicine, Birmingham, AL, USA; 'Department of Ophthalmology, Leiden University Medical Center, Leiden, The

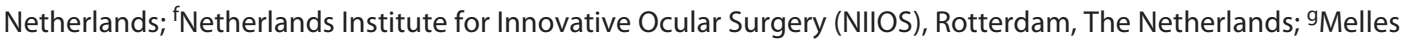 \\ Cornea Clinic Rotterdam, Rotterdam, The Netherlands
}

\section{Keywords}

Corneal transplantation · Keratoconus · Corneal

endothelial dysfunction - Descemet membrane endothelial keratoplasty · Bowman layer transplantation

\section{Abstract}

For nearly a century, the definitive treatment of many corneal dystrophies and ectactic disorders was limited to penetrating keratoplasty, but over the past 2 decades, a surge of surgical innovation has propelled the treatment of many corneal diseases to more targeted approaches with significantly better visual outcomes. Anterior stromal diseases were first changed through endothelial-sparing techniques, such as deep anterior lamellar keratoplasty, but have more recently transitioned to stromal-sparing approaches. Ultraviolet corneal crosslinking strengthens the cornea and halts progression of keratoconus in $>90 \%$ of cases. Intracorneal ring segment and corneal allogenic ring segment implantation offer methods to flatten ectatic corneas. However, Bowman layer transplantation - inlay and more recently onlay techniques - has shown promise for treating advanced keratoconus and preventing keratoplasty. The advent of endothelial keratoplasty radically changed the treatment of cor- neal endothelial dysfunction, and Descemet membrane endothelial keratoplasty specifically offers an average postoperative visual acuity of $20 / 25(0.8)$ with only $8.8 \%$ of grafts requiring retransplantation in the first 5 years. Here, we review the rapid innovations for surgical treatment of corneal diseases, spanning from endothelial keratoplasty and endothelial regeneration to anterior lamellar keratoplasty and stromal augmentation, highlighting key steps which may be moving us closer to a "postkeratoplasty" world.

(c) 2021 The Author(s)

Published by S. Karger AG, Basel

\section{Introduction}

For $>100$ years, penetrating keratoplasty $(\mathrm{PK})$ was the singular transplantation option for severe corneal disorders. As a result, historically, improvements in the field of keratoplasty were largely limited to refinements in the penetrating technique, namely, updates in suture materials, trephines, and microscopes.

The past 20 years, however, have seen an explosion in new partial thickness or lamellar transplantation options. These include various methods for posterior lamellar kera-
(C) 2021 The Author(s)

Published by S. Karger AG, Basel

This is an Open Access article licensed under the Creative Common Attribution-NonCommercial-4.0 International License (CC BY-NC) (http://www.karger.com/Services/OpenAccessLicense), applicable to the online version of the article only. Usage and distribution for commercial purposes requires written permission.
Correspondence to:

Jack Parker, jack.parker@gmail.com 
toplasty (PLK), intended for patients with corneal endothelial disorders, and anterior lamellar keratoplasty (ALK), intended for patients with anterior stromal disorders.

Now, for instance, isolated endothelial failure is treated almost exclusively in the USA and most of the developed world via some form of PLK. The prognosis for these patients is tremendously improved, with PLK providing better visual outcomes, more rapid visual rehabilitation, fewer complications, and fewer postoperative burdens.

These advantages over conventional $\mathrm{PK}$ have led to the widespread adoption of PLK globally and for more complicated eyes. Meanwhile, PLK itself has undergone a number of internal revisions with the donor grafts becoming thinner and more selective. Even more recently, questions have arisen whether a donor graft is even necessary at all, or whether mere removal of the dysfunctional Descemet membrane (DM) and endothelium may permit spontaneous healing with proliferation or migration of the patient's own endothelial cells.

Evolving in parallel have been the ALK techniques. Currently, the most common indication for some form of ALK is advanced keratoconus (KC). Because KC often affects children and young adults (populations with inflammatory phenotypes, active lifestyles, and questionable medical compliance), there is a need to minimize surgical invasiveness. Traditionally, PK has been a risky procedure for this population, since the operation involves the transplantation of large amounts of highly immunogenic tissue and requires a lifetime of postoperative follow-up. ALK may ameliorate some of these concerns because, by avoiding transplantation of the endothelium, the antigenic load of the donor graft is significantly reduced, reducing the risk of allograft reaction and the need for intensive postoperative surveillance.

However, PLK has undergone a series of internal revolutions with many fundamental changes, and ALK has experienced a more moderate course of incremental improvement. An exception to ALK's incrementalism, however, may be recent experiments with isolated Bowman layer (BL) transplantation. In contrast to most ALK techniques, BL transplantation aims to selectively supplement corneas with a thin layer of acellular stroma, without removing any of the recipient corneal structure. Therefore, the operation may avoid some of the most common and severe difficulties of conventional ALK, including those relating to surface incisions, allograft reaction/graft rejection, and suture-related complications.

Presently, BL transplantation may be in its early stages, and refinements to the operative technique and to the do- nor graft preparation may be warranted before the technique achieves widespread adoption. If so, its trajectory may resemble that of PLK, which likewise represented a theoretical step forward, requiring years of refinement before attaining sufficient ease and simplicity to become the global standard of care for endothelial disorders.

\section{Corneal Anatomy}

Among the major structures of the human eye are the cornea, iris, lens, retina, choroid, and the optic nerve, although presently only the cornea is amenable to transplantation. It consists of 5 anatomic layers (from anterior to posterior): the epithelium, $\mathrm{BL}$, stroma, $\mathrm{DM}$, and endothelium.

\section{The Epithelium}

The corneal epithelium is constituted by $5-7$ layers of nonkeratinized, stratified, squamous epithelial cells admixed with a scattering of sentinel cells of the immune system including macrophages, lymphocytes, melanocytes, and Langerhans cells $[1,2]$. Its optical quality derives from the evenness and regularity of its apical surface, the constancy of its thickness (precisely regulated at $50-52 \mu \mathrm{m}$ ), the scarcity of organelles, and the presence of the intracytoplasmic enzyme crystalline within corneal epithelial cells [2-4]. The corneal epithelium's basal layer contains cells linked to each other by desmosomes and tight junctions and to their underlying basement membrane by hemidesmosomes. These cells migrate into the corneal center from the periphery (horizontally) and then up toward the corneal surface (vertically); their origin appears to be a population of stem cells, located at the corneal limbus, the loss of which predisposes the cornea to persistent or nonhealing corneal epithelial defects [5]. Above the basal epithelial layer are 2-3 layers of wing cells, linked by zona occludens, followed by the superficial-most cells of the cornea, which are connected by tight and adherens junctions that tightly regulate corneal-environmental exchange [6].

\section{The BL}

The cornea's BL consists of a thin swath of modified anterior stroma lying immediately beneath the epithelial basement membrane. Approximately 8-14 $\mu \mathrm{m}$ thick (thinning with age), BL is acellular, physically robust, and tenaciously adherent to the underlying stroma [7]. Like the stroma, it consists mostly of types V and I collagen, although its fibers are smaller and more randomly ar- 
ranged $[8,9]$. Surprisingly, the physiologic purpose of this discrete structure remains, to date, unclear.

Some have speculated that it functions as a strong barrier to the passage of pathogens (especially viruses) through the cornea and into the deeper structures of the eye [10]. And undoubtedly, the focal loss of BL does permit aberrant epithelial-stromal communication, which is evident in the fibrous scars that frequently form at those sites [11-14]. In addition, BL may also have some structural role in maintaining the shape/tectonic stability of the cornea, since for corneal ectasias - the earliest and most sensitive indicator of disease is $\mathrm{BL}$ degeneration $[15,16]$. However, because the deliberate and widespread destruction of BL by photorefractive keratoplasty (PRK, a common laser refractive procedure) only rarely destabilizes the cornea into severe ectasia, the architectural raison d'etre of BL must be more complicated and remains poorly understood [17]. Because BL exists as an independent structure, after debriding the overlying epithelium, it may be peeled as a single sheet from the underlying stroma, after which it reliably scrolls into a single or double roll secondary to the inherent elasticity of the tissue itself $[14,18]$.

\section{The Stroma}

Stroma represents the bulk of the thickness and weight of the cornea: it is constituted by collagen fibrils (predominantly types I and V) arranged into 200-250 layered sheets (lamellae) that are oriented obliquely and with interlacing fibers connecting the layers together [1]. The posterior-most layer(s) of the stroma (the so-called "Dua layer") appears morphologically identical to the adjacent stroma but may exhibit specialized behaviors owing to its location [19-22]. Interspersed among the collagen fibers are glycoproteins, which attract cations and water and therefore tend to cause the cornea to swell (this tendency must be counteracted by the endothelial pump function, to be discussed below). These glycoproteins, and the collagen structure of the stroma itself, are secreted and maintained by a population of highly metabolically active corneal keratocytes, which are most numerous in the anterior cornea [1].

\section{The Pre-Descemet Stroma}

The injection of air or viscoelastic into the deep stroma of a human cornea does not infrequently produce a cleavage plane between the bulk of the stroma (anterior) and a thin layer of anatomically indistinct stroma of variable thickness which immediately overlies the Descemet layer (posterior) [19-22]. This thin band of pre-Descemet stroma is otherwise known as the Dua layer, and while its ex- istence has been long recognized, its importance may only be recently understood [23].

Being composed of multiple collagen layers, the preDescemet stroma may confer an additional element of strength and support potentially advantageous in certain surgical circumstances. Specifically, during "big bubble" anterior lamellar procedures, it may protect against inadvertent rupture of the DM (itself a structure with very low tensile strength) and perforation into the anterior chamber. The pre-Descemet stroma may also be incorporated into a Descemet membrane endothelial keratoplasty (DMEK) graft; this modification has given rise to the modified transplant type "Pre-Descemet endothelial keratoplasty" (PDEK), originally described by Agarwal et al. [24]. Compared to conventional DMEK, PDEK may provide easier to handle tissue intraoperatively and the ability to use younger human donor tissue [25]. On the other hand, known PDEK disadvantages include smaller graft diameters (carrying fewer endothelial cells) and the possibility of optical interference generated by the additional stromal elements $[26,27]$. High tensile strength is among the most notable features of the pre-Descemet stroma; some have speculated that - as a result - there may be ruptures in this tissue, rather than the relatively weak DM that is responsible for the explosive deterioration seen with corneal hydrops in eyes with $\mathrm{KC}$, and that, further, previously thought "descemetoceles" may instead be "Dua-celes" [28].

\section{The DM}

$\mathrm{DM}$ is the basement membrane of - and secreted by - the cornea's endothelium and lies sandwiched between the endothelium (below) and the posterior stroma (above). Composed largely of type IV collagen and laminin, it comprises 3 distinct layers: a thin nonbanded zone ( $0.3 \mu \mathrm{m}$ thick) immediately adjacent to the stroma, an anterior banded zone $(2-4 \mu \mathrm{m})$ that thickens with advancing age, and a posterior/amorphous nonbanded zone $(>4 \mu \mathrm{m})$ that features an atypical striate pattern of degeneration and wart-like collagenous excrescences known as guttae in patients with Fuchs endothelial dystrophy $[29,30]$. As a membrane with only tenuous connections to the overlying stroma, DM is easily stripped free as a single sheet (along with its attendant endothelium), which - like BL - also curls spontaneously into a single or double roll upon separation, owing to its own internal elasticity [31, 32].

\section{The Endothelium}

The endothelium exists as a monolayer of tightly packed hexagonal cells that comprise the cornea's poste- 
rior surface. The number of endothelial cells per unit area is regarded as the endothelial cell density (ECD), which is maximum at birth (around 6,000 cells $/ \mathrm{mm}^{2}$ ), declines sharply in the first year of life (to approximately 4,000 cells $/ \mathrm{mm}^{2}$ ), and then decreases gradually by $\sim 3 \%$ per year until adulthood, when the loss rate slows to $\sim 1 \%$ per year, so that by late age, most people have approximately $2,000-2,500$ cells $/ \mathrm{mm}^{2}[33,34]$. Aside from aging, other causes of reduced ECD include prior intraocular surgery, elevated eye pressure, trauma, prolonged contact lens (CTL) wear, and chronic anterior chamber inflammation [35]. Polymegathism and pleomorphism are the hallmarks of diseased or damaged endothelium: as cells are lost, neighboring cells expand to fill the vacated space producing a cobblestone pattern of variably sized and irregularly shaped cells $[35,36]$. Specular microscopy readily demonstrates these changes in vivo in patients with endothelial diseases and may be used to track corneal health over time [37].

\section{Endothelial Migration and Proliferation}

The prevailing research suggests that, in vivo, endothelial cells neither proliferate nor replicate and remain permanently confined to a premitotic, G1-phase [38]. While no definite explanation for this arrest in cell development has been discovered, candidate explanations include the absence of autocrine/paracrine mitogenic stimulation, negative regulation by transforming growth factor beta (a substance that - when combined with aqueous humor - may inhibit entry into the S-phase), and cell contact inhibition (a process mediated by p27kip1, a known G1-phase inhibitor) $[38,39]$. Endothelial depletion from the central cornea prompts the inward migration of cells from the periphery to fill the vacancy. Although, previously, it was believed that these peripheral cells may be qualitatively different from central cells, perhaps possessing some additional proliferative potential, recent studies have failed to corroborate this theory $[40,41]$.

Nevertheless, in vitro, the human endothelium does appear capable of (limited) replication and growth, particularly when treated concurrently with ethylenediaminetetraacetic acid, viral oncogenes, or when reared in culture media with select additives including epidermal growth factor, nerve growth factor, basic fibroblast growth factor, and animal-derived extracellular matrix [42-51]. But even under these conditions, the human corneal endothelium cannot be cultured indefinitely or proliferated infinitely: in general, the cells do not survive into the long term and cannot replicate beyond a few generations. This is particularly true for cell lines obtained from older donors ( $>30$ years) which are relatively refractory to mitogenic stimulation and require more and longer exposure before responding $[52,53]$. Interestingly, however, young and old endothelial cells alike contain telomeres of similar lengths [45]. This suggests both a low natural replication rate and that telomere shortening is an unlikely mechanism for the diminished capacity for replication that older cells display, which may - instead - be attributed to accumulating stresses, including (potentially) oxidative damage [52-54].

\section{Corneal Transparency and Hydration: The}

Endothelial Barrier and Pump Function

The transparency of the cornea derives from the diameter and spacing of the collagen fibers that compose it. Because both are smaller than half a wavelength of light, $90 \%$ of the incident light passes through, amplified by constructive interference, whereas nearly all scattered light is dissipated by destructive interference. As a result, under normal circumstances, the cornea - although constituted largely of the same material as the adjacent sclera (which is totally opaque) - remains clear [55-58]. However, if its architecture is disturbed such that the caliber or distance between collagen fibers is affected (e.g., by scarring or fluid accumulation), then the delicate interference patterns that selectively transmit incident and rebuff scattered light are ruined, resulting in focal opacities.

\section{Corneal Hydration}

The cornea's water content ( $78 \%$ by weight) is tightly controlled by 2 principal means: the epithelial barrier and the endothelial pump [59-61]. At the ocular surface, tight junctions between epithelial cells keep fluid out from above. Meanwhile, with eyes open, evaporation from the tear film creates an osmotic gradient that draws water up from the stroma below.

Along the cornea's posterior surface, endothelial cells are likewise bound together by tight junctions, albeit with frequent gaps, permitting some fluid leakage up into the stroma. This constant leak provides the primary supply of glucose, amino acids, and other nutrients to the avascular cornea. Meanwhile, the "endothelial pump" (really, a complex chain of ion transporters) creates a countercurrent, which - by osmotic gradient - directs fluid back out of the stroma and recycles it into the anterior chamber, thereby balancing the passive influx [59-62].

\section{Endothelial Barrier and Pump Function}

Carbon dioxide $\left(\mathrm{CO}_{2}\right)$ passively diffuses into endothelial cells. There, it combines with $\mathrm{H}_{2} \mathrm{O}$ to form carbonic 
acid $\left(\mathrm{H}_{2} \mathrm{CO}_{3}\right)$ and is cleaved by carbonic anhydrase into hydrogen ions and bicarbonate $(\mathrm{H}+$ and $\mathrm{HCO} 3-)$, both of which are then actively pumped into the stroma [63, 64].

The bicarbonate is allowed back into the cell by the cooperative actions of 2 basolateral channels: the $\mathrm{Na}+\mathrm{K}+$ ATPase and the $1 \mathrm{Na}+-2 \mathrm{HCO} 3-$ cotransporter. The former pumps sodium against its concentration gradient into the stroma, and the latter permits the ion's return, along with 2 molecules of bicarbonate. Sodium also returns to the cell via basolateral $\mathrm{Na}+-\mathrm{K}+-2 \mathrm{Cl}-$ transporters and $\mathrm{Na}+-\mathrm{H}+$ exchangers. Principally, it is the net influx of bicarbonate (and possibly also $\mathrm{NaCl}$ ) that drives the osmotic gradient which draws water out of the stroma and deturgesses the cornea [65-70].

\section{Corneal Transplantation}

Corneal transplantation (or simply, keratoplasty) involves the exchange of donor corneal tissue - as a graft - for the patient's own diseased cornea (or a portion of it). Although the operation may also be performed for tectonic and cosmetic reasons, its most common indication is visual restoration [71]. Originally, the surgery amounted to little more than simple substitution: after excising practically the whole recipient cornea, a donor graft was sewn into position, effectively replacing the entire organ. This type of whole-corneal transplantation is traditionally known as PK and is still performed today, although now less commonly, since the advent of modern partial corneal (lamellar) transplantation $[71,72]$.

\section{Early Efforts}

Scientific inquiry into the possibility of corneal transplantation began in the late 1700s. By the 1820s, the idea had matured, and the term "keratoplasty" arose to designate the surgical procedure (coined independently by Himley and Reisinger [72]). Virtually all initial attempts at the operation were failures, as the early donor tissue came from animals and succumbed invariably to immunological rejection [73]. Consequently, the first successful corneal transplant was delayed until 1905 when a Slovakian ophthalmologist, Dr. Eduard Zirm, performed bilateral corneal replacement for a patient previously blinded by a chemical accident [74].

With the essential technique established, next came improvements in tissue and tools. The Russian ophthalmologist Vladimir Filatov popularized the use of cadaveric human corneas for donor grafts and thereby estab- lished himself as the father of modern eye banking [75]. In Spain, Ramon Castroviejo performed his first successful keratoplasty in 1936 and subsequently devised a litany of useful instruments to facilitate the procedure [76]. Prophylactic antibiotics became stronger and more routine in the 1940s, steroids emerged to temper postoperative inflammation, and better corneal preservation protocols and upgraded technology (in particular, operating microscopes which enabled modern microsurgery) pushed surgical outcomes to new heights [77].

Meanwhile, eye banks developed in parallel. The first was created in New York in 1944 by Townly Paton [78]. In 1961, the Eye Bank Association of America (EBAA) was founded and established standards for obtaining, processing, storing, and using donor tissue. By incorporating specular microscopy, eye banks learned to scrutinize the endothelial health of their corneas and to offer exclusively high-quality tissue [79]. Finally, the development of MK medium by McCarey and Kaufman in 1974 enabled corneal preservation, permitting grafts to be stored and transplants planned and scheduled in advance [80].

\section{Evolving Techniques in Corneal Transplantation}

Despite these revolutions in medication, instrumentation, and tissue preservation, the basic goal of the operation remained the same: total replacement of the recipient cornea with donor tissue. Complete corneal exchange (PK) therefore represents the overwhelming history of the surgery [81]. It was the first, and - until at least the 1970 s - the only form of corneal transplantation commonly available. Nevertheless, the operation was prone to problems, deriving principally from the bulk of the grafts and from the incisions necessary to accommodate them. Such problems include poor wound healing, suture-related difficulties, an unstable ocular surface, the persistent threat of allograft reaction and graft rejection, and frequently, disappointing visual outcomes [82].

The first attempts at partial corneal transplantation (lamellar keratoplasty) occurred in the 1950s. While Jose Barraquer experimented with replacing the anterior corneal surface, Charles Tillet trialed posterior lamellar exchange [83, 84]. Ultimately, however, both efforts failed: Barraquer's because the irregular interface between the donor and recipient tissues degraded the cornea's optical results, and Tillet's because fixating a posterior lamellar graft to the overlying stroma proved impossible with conventional suturing techniques. Sunk by disappointing results like these, lamellar keratoplasty was mostly forgotten and largely abandoned for decades [85]. 
But in the 1980s, interest in anterior lamellar exchange was revived: Eduardo Archila [86] demonstrated that an intrastromal injection of air could facilitate deeper dissection into the recipient cornea, significantly reducing the irregularity at the graft interface. This gave rise to the concept of deep anterior lamellar keratoplasty (DALK). Anwar and Teichmann [87] refined the technique by establishing that a single "big bubble" could be generated between the recipient stroma and its DM, and that - by expanding this bubble - the 2 tissues might be totally separated. Independently, Melles et al. [88] showed that a similar feat was possible using viscoelastic instead of air. They also devised a method for manually dissecting the entire host stroma from its DM using a series of curved spatulas and the "air-endothelium reflex" (the location of the reflection produced by the tips of his instruments) to precisely judge the depth of the ongoing dissection [89]. Meanwhile, they also solved the primary problem with posterior lamellar transplantation: fixating the grafts to the recipient's stroma. Although prior attempts to suture the donor tissue had failed, they discovered that - in-stead - an air bubble could be left inside the anterior chamber, and the force of its buoyancy sufficed to hold the graft in place. As a result, in 1998, PLK became feasible [90]. In the USA, the operation was rebranded deep lamellar endothelial keratoplasty (DLEK) by Terry and Ousley [91]. But, because DLEK proved too technically challenging for widespread adoption (since it required meticulously dissecting matching stromal/endothelial lenticules from the recipient and the donor corneas, then exchanging them), Melles et al. [92] revised the procedure into a modified version which he dubbed Descemet stripping endothelial keratoplasty (DSEK). Compared to DLEK, DSEK was simpler and easier: while the 2 operations employed identical donor tissue, DSEK abandoned the stromal dissection that DLEK required in favor of merely stripping the recipient endothelium and DM. This dramatically lessened the technical challenge of the surgery and established DSEK as the global treatment of choice for endothelial disorders, especially after Mark Gorovoy [93] popularized the use of microkeratome-cut DSEK grafts (thus effecting a tweak to the nomenclature: Descemet stripping automated endothelial keratoplasty, DSAEK).

Although an improvement over DLEK, DS(A)EK nevertheless retained some of its predecessor's limitations. In particular, both operations entailed the transplantation of some amount of donor stroma into the recipient eye, and this extra tissue probably compromised the cornea's optical performance [94]. Consequently, Melles et al. [95] further refined the operation to DMEK, which differed from
DSEK in that its graft was constituted exclusively of DM and its endothelium, without any attendant stroma. Therefore, with DMEK - and for the first time in the history of posterior lamellar exchange - an exact one-to-one exchange of the donor for diseased tissue was achieved, and the natural, physiologic anatomy of the cornea was restored [96].

Endothelial keratoplasty is the umbrella term that has emerged to describe these various formulations of posterior lamellar transplantation (PLK, DLEK, DS(A)EK, and DMEK). Although PLK and DLEK have been largely superseded, DS(A)EK and DMEK currently coexist as the 2 most common treatments for endothelial dysfunction worldwide [97]. Since their original description, both operations have changed considerably: in general, DS(A)EK grafts have gotten thinner (i.e., they incorporate less donor stroma), promoting better visual outcomes through reduced scarring at the transplant interface [98]. Meanwhile, DMEK grafts have likewise experienced several shape changes. Until recently, all consisted of circular sheets of DM and endothelium cut from the center of donor corneas. But in 2014, it was discovered that rather than harvesting merely the central, circular, island of DM and endothelium, instead the entire sheet could be bisected and then stripped to produce 2, large, hemicircular grafts, each of which may be transplanted into separate patients [99]. This new surgical variant has been named hemi-DMEK, and it appears to offer results comparable to conventional DMEK while doubling the pool of donor tissue available for transplant $[100,101]$. Even more recently, quarter-DMEK has been described, which takes the logic of hemi-DMEK one step further, by dividing a single donor DM into 4 transplantable, pie-shaped grafts [102-104].

Aside from hemi- and quarter-DMEK, other proposed modifications to the basic DMEK technique include Descemet membrane endothelial transfer (in which a DMEK graft is injected into the recipient eye but not apposed against the host stroma, and temporary corneal clearance occurs after some delay by endothelial cell migration, although usually followed by repeat corneal decompensation), DMEK-S (a largely abandoned way to prepare DMEK grafts by microkeratome that leaves the tissue with a rim of stroma to facilitate intraoperative handling), and PDEK (which is similar to conventional DMEK except that the graft is $20-\mu \mathrm{m}$ thicker because it also incorporates a thin layer of posterior stroma) [105-108].

Alongside these innovations in posterior lamellar transplantation, recently, a new operation has emerged for patients with corneal ectasias: BL transplantation 
[109]. The procedure entails implanting a graft consisting of an isolated, donor BL. Subsequent healing both flattens and "fixes" the cornea into a more normal configuration that resists further disease progression $[109,110]$. Thereby, corneal ectasias may be halted (even partially reversed). And, because the operation makes no surface incisions, requires no sutures, and transplants only thin, acellular material (and thus provokes little-to-no immunological reaction), BL transplantation may avoid many of the most common complications of PK and even DALK [111].

\section{Anterior Lamellar Keratoplasty}

\section{The Current Landscape of Treatment Options}

For the treatment of $\mathrm{KC}$, as for glaucoma, there has been a new surgical emphasis on "minimally invasive" techniques. Primarily, these techniques have been targeted at patients with mild to moderate disease and include ultraviolet corneal crosslinking (UVCXL) and intracorneal ring segment (ICRS) implantation. There remains, however, a need for less treatments for patients with advanced $\mathrm{KC}$.

UVCXL may only be appropriate for patients with mild to moderate disease. The minimum corneal thickness required to safely proceed with the procedure is 400 $\mu \mathrm{m}$, which may be disqualifying for patients with more advanced $\mathrm{KC}$ and more severe thinning $[16,17]$. Corneas with maximum keratometry $\left(K_{\max }\right)$ values exceeding 58 diopters (D) may also be less likely to respond to crosslinking and may continue to progress after treatment $[16$, 17]. Likewise, UVCXL may be practically difficult to perform in very young patients or patients with comorbid mental or behavioral limitations, since cooperation may be limited $[16,17]$. In addition, at least in the USA, insurance payment and reimbursement obstacles have rendered UVCXL logistically difficult to perform at times, even as late as 2020.

ICRS implantation has faced similar obstacles. Severe corneal thinning is disqualifying, since a corneal thickness of at least $400 \mu \mathrm{m}$ is necessary at the incision site (otherwise, there is an unacceptably high risk of segment extrusion and overlying corneal melt) $[16,17]$. In addition, one of the major purported benefits of ICRS implantation is the possibility of improved vision. However, patients with a $K_{\max }>58 \mathrm{D}$ often realize disappointing visual gains because the segments are unable to correct a sufficient amount of corneal warpage to generate a noticeable improvement in visual acuity $[16,17]$. Addition- al limitations to ICRS also apply. For instance, patients with corneal scarring are ineligible for this procedure, and as with UVCXL in the USA, insurance reimbursement hurdles have rendered ICRS not widely available, even for qualifying patients $[16,17]$.

As a result, particularly for patients with advanced $\mathrm{KC}$, the only widely available surgical option in the USA has historically been PK. DALK has been introduced as an alternative, although in the USA in particular, the operation has remained unpopular, possibly relating to the enhanced technical difficulty of the procedure. Theoretically, DALK may be preferred to PK because, by avoiding the transplantation of the donor endothelium, the risk of allograft reaction and graft rejection may be reduced. However, because the operation still involves large surface incisions on the recipient cornea and sutured donor material, many of the traditional risks and limitations of PK continue to apply.

In the past decade, isolated BL transplantation has been described as an alternative to PK and DALK for patients with advanced $\mathrm{KC}[112,113]$. Because the BL graft is acellular and is implanted in a suture-less fashion within the corneal stroma of the recipient eye, many of the limitations and complications of PK and DALK may be avoided. In addition, because the BL graft may stabilize and flatten the recipient cornea, many of the advantages of UVCXL and ICRS may be captured and applied to eyes in which these procedures would normally be contraindicated. However, one of the major obstacles for the popularity of this surgery is the difficulty of a midstromal dissection in extremely thin, severely ectatic corneas; therefore, efforts to automate this step with a femtosecond laser have been attempted, and while this technique may offer a safer and more accurate stromal dissection, longer-term results are needed to assess its effects on corneal curvature [112].

$\mathrm{BL}$ onlay was introduced to make the surgery more "user friendly" by placing the graft in its anatomic position on the anterior surface of the stroma, making it a truly extraocular procedure $[114,115]$. Early outcomes suggest it is equally as effective for treating $\mathrm{KC}$ as its inlay counterpart but can additionally be used for the treating anterior stromal herpetic scars and corneal instability following radial keratotomy $[114,115]$.

Jacob et al. [116] introduced a new surgery similar to ICRS implantation, called corneal allogenic intrastromal ring segment (CAIRS) implantation. Like ICRS implantation, semicircular stromal channels are created, but for CAIRS, the channel is made at $50 \%$ depth instead of $75 \%$ depth. Instead of inserting an arc-shaped polymethyl- 
Fig. 1. Intraoperative video stills of a $\mathrm{BL}$ transplantation. Scleral tunnel incision (a) and paracenteses (b) are made. c Then, the anterior chamber is filled with air, and a manually dissected midstromal pocket is created, using different sized spatulas (df). $f$ As an indication for the dissection depth, the "thin black line" alongside the spatula can be used. After removing most air from the anterior chamber, the BL graft is inserted into the pocket atop of a glide ( $\mathbf{g}$, h) and then carefully unfolded and centered with a $30-G$ cannula (i). j After complete unfolding and positioning, the $\mathrm{BL}$ graft is sandwiched between the anterior and posterior stromal layers. No sutures are necessary to fixate the graft or to close the tunnel incision (reprinted from Dragnea et al. [113] with permission). BL, Bowman layer.
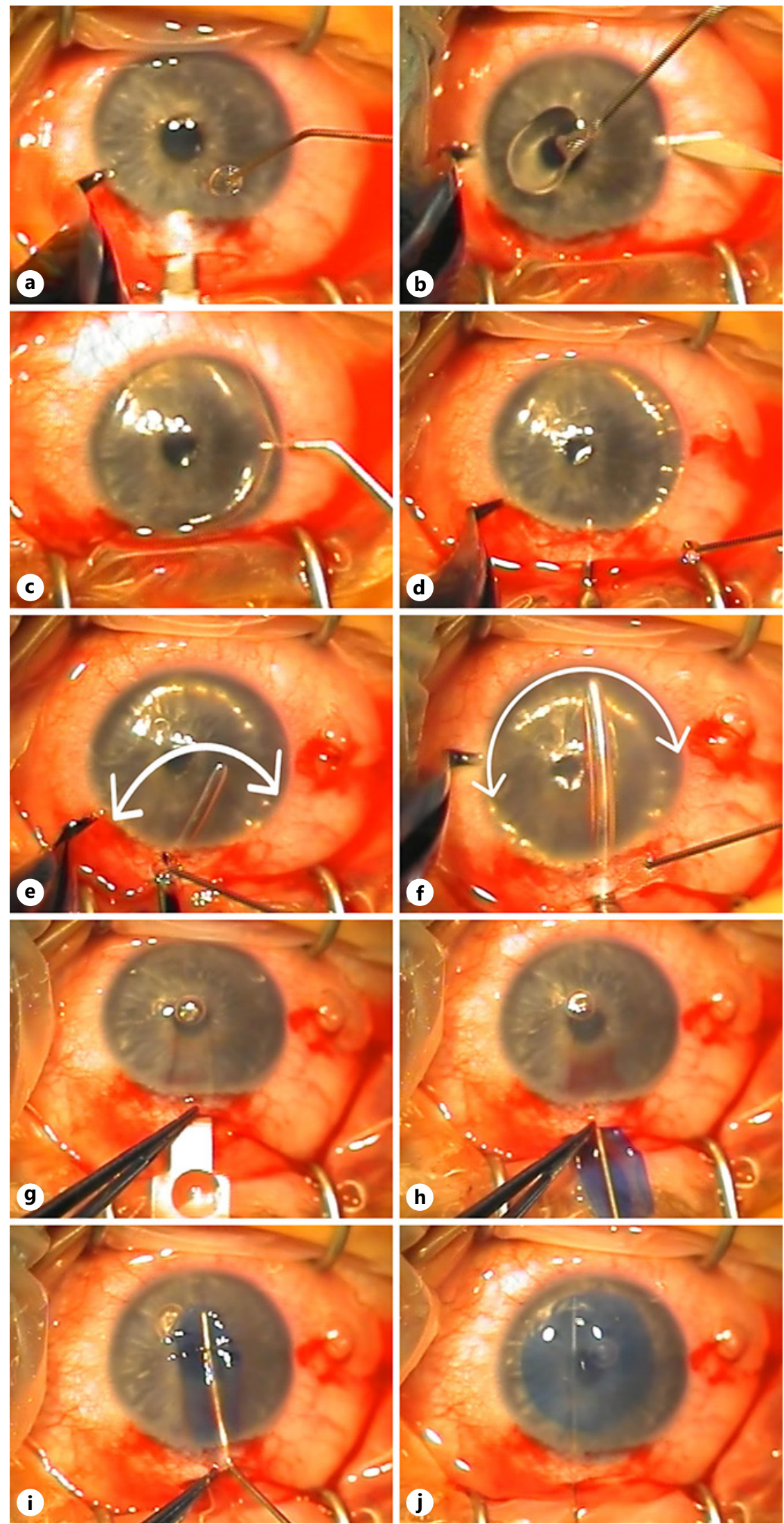
methacrylate segment, a similarly shaped strip of donor corneal stroma is implanted in the midstromal semicircular channel. This surgery was developed because of the postoperative risks with ICRS implantation, specifically stromal melt and extrusion of the segments. CAIRS implantation not only theoretically reduces these complication risks but also is doable in eyes with advanced $\mathrm{KC}$. Additionally, the original technique combined ring segment implantation with UVCXL by first soaking the segments in a riboflavin solution, which acts as the photosensitizer during crosslinking but also aids in visualization of the segment during implantation [116]. Where combination of these 2 procedures is not possible, the CAIRS segments can be rinsed in trypan blue to assist with segment visualization [117]. So, while UVCXL and ICRS still remain the standard for eyes with mild to moderate $\mathrm{KC}$, these innovative corneal grafting techniques may provide minimally invasive options for patients with even advanced KC [118].

\section{The Introduction of Isolated BL Grafting}

Fragmentation of the cornea's BL has been described as one of the earliest manifestations of KC. It is a mechanical insult which may critically destabilize the cornea and predispose it to ongoing ectasia.

Isolated BL transplantation has been previously described to treat patients with postrefractive haze following laser surface ablation [109]. By re-establishing a barrier between the normal epithelium and the underlying anterior stroma, the normal anatomy of the recipient eye was restored, which resolved the haze associated with the prior laser procedure. This operation proved the possibility and viability of BL transplantation as a concept [109].

In 2013, Van Dijk et al. [109] therefore attempted isolated BL transplantation for eyes with advanced $\mathrm{KC}$ who were otherwise ineligible for more conservative treatment options (i.e., UVCXL and ICRS) because of extreme steepening and thinning. Ten eyes of 9 patients with advanced, progressing KC and CTL intolerance were selected for the initial cohort of trial patients [109]. All received a BL "inlay" via a standard surgical technique: a superior conjunctival peritomy was created, followed by a $5-\mathrm{mm}$ partial thickness scleral incision, which was tunneled up into the peripheral clear cornea using a crescent blade. Then, the Melles DALK dissection spatulas were used to create a pocket, aiming at $50 \%$ stromal depth, from limbus-to-limbus, $360^{\circ}$ around within the recipient corneal stroma. This dissection was facilitated by first filling the anterior chamber with air via paracentesis and then using the air-endothelial reflex to guide the depth of dissection. After the pocket was created, air was evacuated from the anterior chamber, and then a surgical glide was placed into the mouth of the corneoscleral incision. The isolated BL graft was then removed from storage solution, rinsed with saline, stained with trypan blue, flushed with a $70 \%$ ethanol solution to remove any lingering epithelial cells, and then rinsed again with saline. Then, the graft was placed onto the surgical glide and advanced into the manually dissected corneal pocket by pushing it with a cannula. Once the graft was entirely inside the corneal pocket, the surgical glide was removed, and graft unfolding proceeded by direct manipulation with the cannula and indirect manipulation via bursts of saline. Once the graft was fully unfolded and centered within the corneal pocket, the anterior chamber was reformed using saline, and the conjunctival peritomy was repaired to conclude the operation. Postoperatively, patients used a topical antibiotic for 1 week and a topical steroid for 6 months (Fig. 1).

No intra- or postoperative complications were experienced. After surgery, maximum keratometry $\left(K_{\max }\right)$ declined by an average of 7.3 diopters (D). CTL tolerance was restored in all eyes, and no keratoconic progression was observed in any eye [109].

This initial report established the plausibility of isolated BL transplantation to halt the progression of corneal ectasia in patients with corneas too thin and/or too steep for conventional disease-arresting therapies (UVCXL or ICRS). In addition, BL transplantation seemed to achieve a positive anatomic effect of significantly flattening recipient corneas, with the result of improved spectacle-corrected vision and ability to tolerate CTL wear [109].

Moreover, because the BL graft is acellular tissue, the risk of allograft rejection/graft rejection is regarded as low, and therefore patients were prescribed only a relatively short duration of topical steroid therapy. Theoretically, this may carry the advantage of reduced postoperative medication burden for the patient and a reduced risk of steroid-related side effects, such as glaucoma and cataract. Finally, because BL transplantation does not involve corneal surface incisions or corneal sutures, the risk of wound dehiscence, infection, and other suture-related complications may be minimized.

A more recent study of 20 eyes confirmed these results, and $84 \%$ of eyes showed stability of $K_{\max }$ values at 5 years [119]. Therefore, BL transplantation may offer a superior safety profile to PK and DALK and represent a reasonable option to preserve or restore CTL tolerance to patients with advanced, progressive KC (Fig. 2). 


\section{$B L$ Transplantation in the USA}

One limitation to the rapid global adoption of $\mathrm{BL}$ transplantation for the treatment of advanced $\mathrm{KC}$ was the perceived technical difficulty, both of graft preparation and surgical technique. The initial operation had been described in the Netherlands in the confines of a dedicated corneal surgical research center with an "inhouse" eye bank. Partially because both the surgical facility and the eye bank were perceived as highly specialized, technical organizations, there may have been some psychological reluctance for other surgeons and facilities to begin with the operation. Therefore, the first reports of BL transplantation at another site may have been important in signaling the technical feasibility and the logistical possibility of the operation throughout the ophthalmic community.

The first report of BL transplantation in the USA was in 2017 [120]. The operation was performed on a young male with progressive advanced KC, ineligible for UVCXL and ICRS implantation in his worse eye. The BL graft was prepared in a local eye bank by the surgeon several days prior to transplantation. The operation itself was uneventful and proceeded according to the previously described Dutch protocol, except for the use of intraoperative anterior segment optical coherence tomography (iOCT) to verify the depth of the dissection and the proper placement of the BL graft. No intraoperative complications were experienced. The postoperative course was likewise unremarkable. Topical antibiotics and steroids were employed for 1 month and then discontinued without tapering.

Following BL transplantation, 5D of central corneal flattening was observed, and comfortable scleral CTL wear was achieved, resulting in a best-corrected vision of $20 / 20$. Since the operation, the graft has remained barely visible as a thin line within the midstroma of the transplanted cornea, appreciable by slit-lamp biomicroscopy.

Since this operation, successful BL transplantation outside of the Netherlands has been reported in multiple other places globally including France, Russia, Brazil, and in other parts of the USA [112]. In general, these independent trials have confirmed the early Dutch results that BL

Fig. 2. Pre- and postoperative clinical images of an eye that underwent BL transplantation. Slit-lamp pictures (a-f), anterior corneal topography $(\mathbf{g}-\mathbf{i})$, and posterior corneal elevation maps $(\mathbf{j}-\mathbf{I})$ of an eye before $(\mathbf{a}, \mathbf{d}, \mathbf{g}, \mathbf{j})$ and at 1 month $(\mathbf{b}, \mathbf{e}, \mathbf{h}, \mathbf{k})$ and 5 years after $(\mathbf{c}, \mathbf{f}, \mathbf{i}, \mathbf{I})$ BL transplantation. Slit-lamp imaging demonstrates a clear cornea preoperatively (a), as well as postoperatively at 1 month (b) and 5 years (c), while the BL graft is visible as a thin transplantation is a technically feasible and generally effective method for flattening and stabilizing corneas with advanced $\mathrm{KC}$, otherwise ineligible for conventional disease-arresting therapies such as UVCXL and ICRS.

In addition, from these various international experiments, several modifications to the originally described technique have been attempted. These include the use of iOCT to help visualize the dissection plane and graft placement and the use of femtosecond laser technology to prepare both the donor tissue and the recipient pocket $[112,120,121]$ (Fig. 3).

\section{Outstanding Controversies in ALK}

Over the last few decades, there has been an explosion of techniques for transplantation of the anterior cornea. Broadly speaking, these techniques include the so-called "big bubble" versus "manual" DALK, as well as BL transplantation. For each of these techniques, internal debates are common pertaining to the nature of the donor tissue and how it should be prepared, instrumentation, and surgical strategy [122].

The first point of argument pertains to graft preparation, including tissue type and instruments used. Although grafts from fresh human corneal tissue are most widely used and boast better visual outcomes, decellularized preserved human corneal tissue grafts can be stored for up to 1 year and evoke a significantly lower rate of allograft reaction, with eyes receiving preserved human corneal tissue grafts preserved with cryotherapy boasting similar short-term visual outcomes as eyes receiving grafts of fresh human corneal tissue but may experience an increase in haze long term. Alternatively, xenotransplantation, which is rarely used in low-income countries only, seems to be safe but with inferior visual outcomes.

For the creation of superficial anterior lamellar keratoplasty grafts, the instrumentation preference varies; while microkeratome dissection is the cheaper option, the use of a femtosecond laser provides for a more accurate and more precise cut. For the creation of DALK grafts, the debate is much simpler: whether to keep the donor DM. While DM-on grafts can expedite the operation and with no decrease in Snellen acuity, they do predispose eyes to

white line within the host stroma (white arrows) (e, f). g-i Corneal topography shows a flattening from preoperatively $(\mathbf{g})$ to the 1-month follow-up (h) and stabilization thereafter (h, i). Likewise, a decrease in posterior corneal elevation can be noticed from before to 1 month postoperatively $(\mathbf{j}, \mathbf{k})$, after which no changes occur up to 5 years $(\mathbf{k}, \mathbf{I})$ after BL transplantation (reprinted from Dragnea et al. [110] with permission). BL, Bowman layer.

(For figure see next page.)

Ophthalmic Res 2021;64:532-553 541 
Preoperative
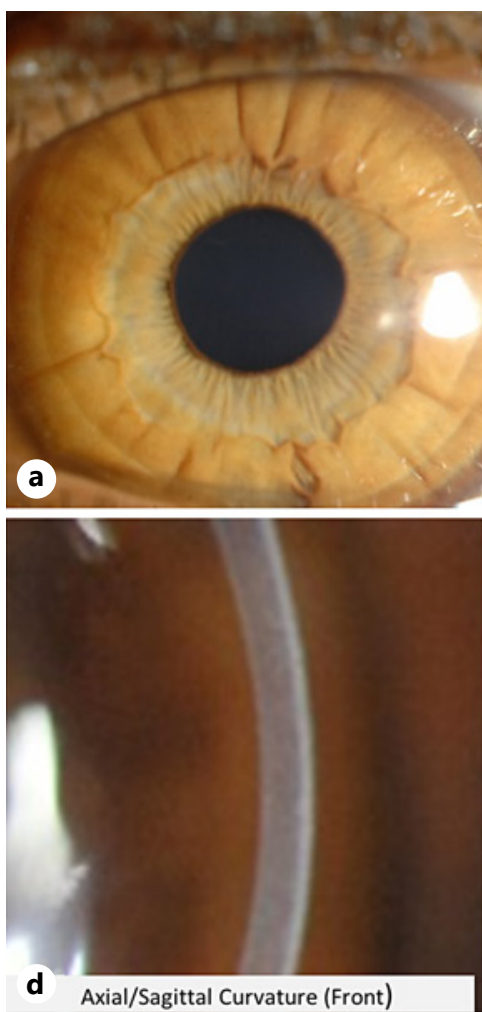

Axial / Sogital Curvature (Front)
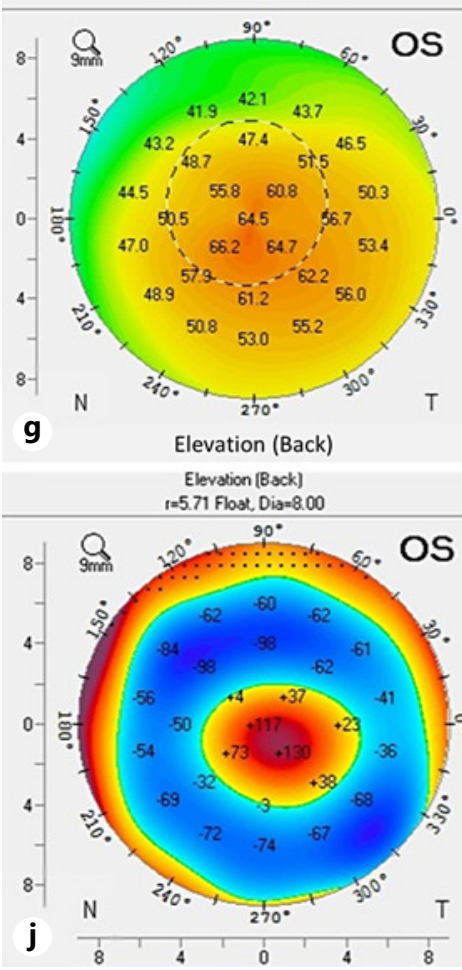

1 month postoperative

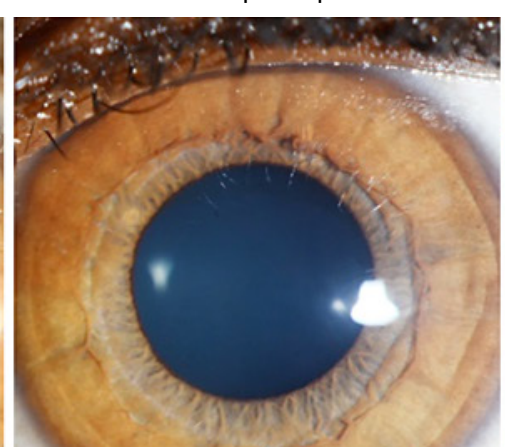

b

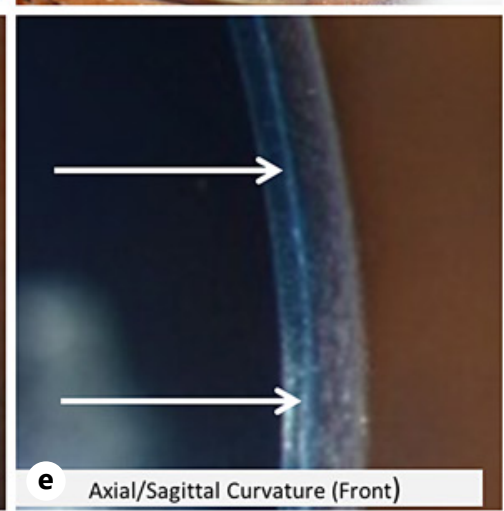

Avial / Sagittal Curvature [Fronk]
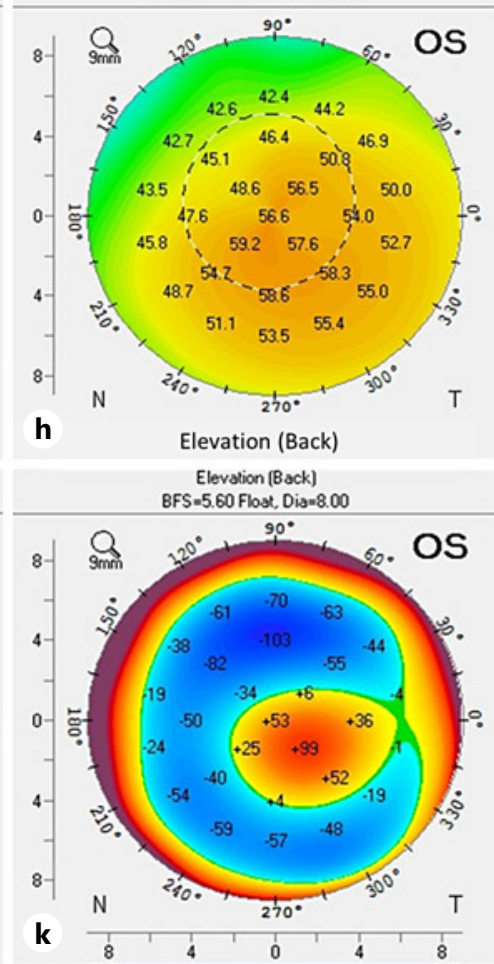

5 years postoperative

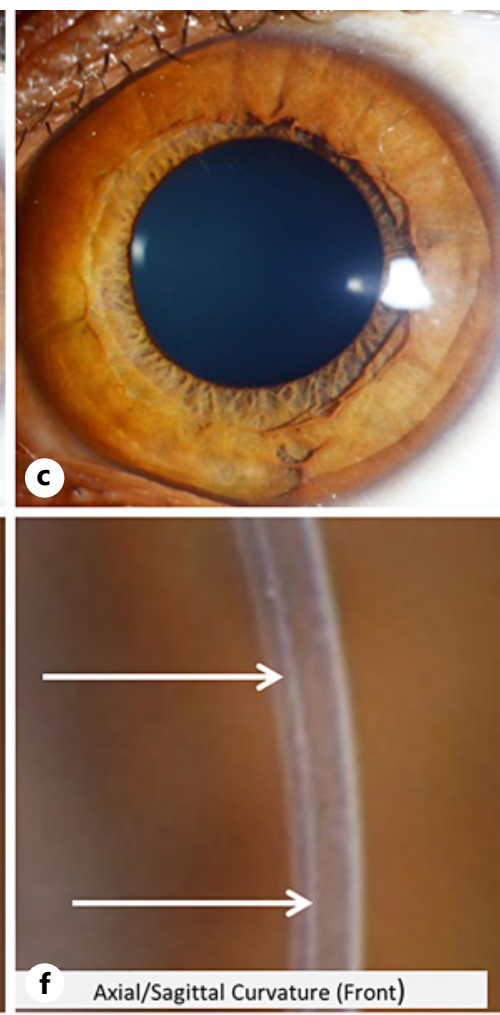

Axial/Sagittal Curvature (Front)

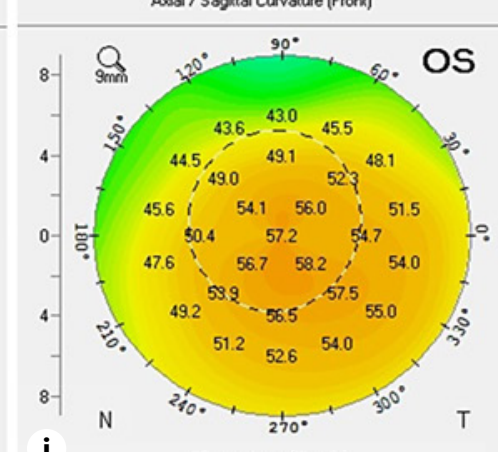

i Elevation (Back)

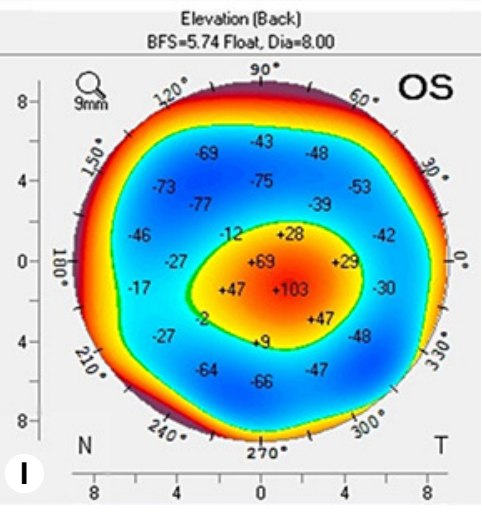



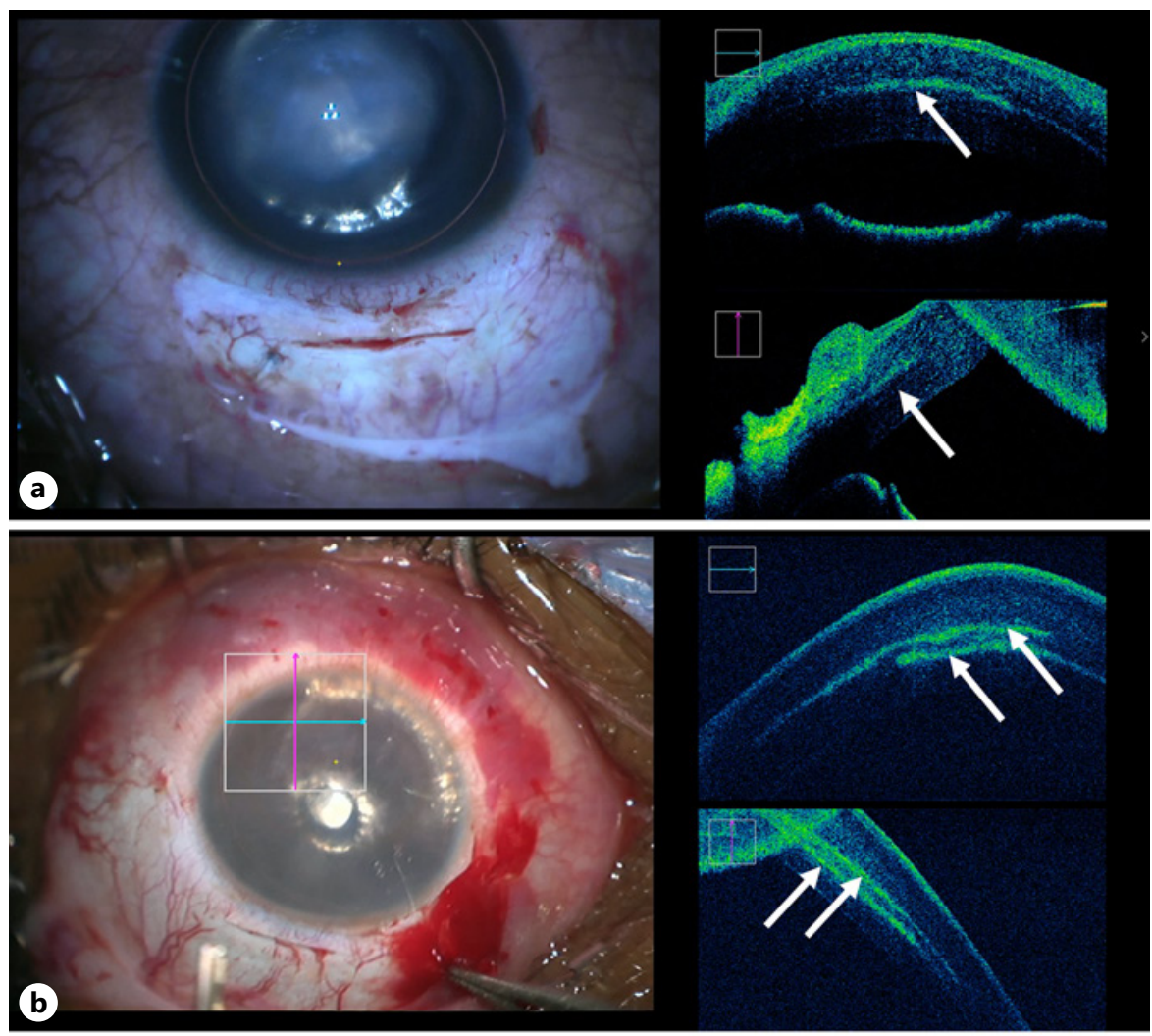

Fig. 3. iOCT revealing the plane of ongoing stromal dissection, even when the surgeon's direct view is obscured by stromal scarring (a). This enhanced visualization may also permit the detection of multiple (mistaken) dissection planes (b) and confirmation of graft placement (c) (reprinted from Tong et al. [120] with permission). iOCT, intraoperative optical coherence tomography.

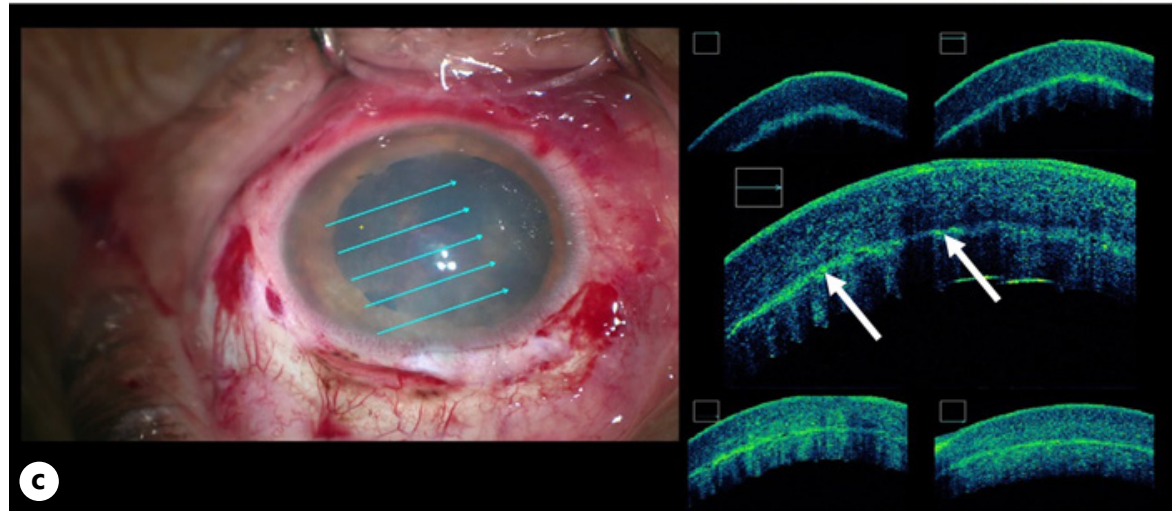

increased postoperative haze and theoretically increased risk of allograft reaction.

For DALK in general, a dissection to the DM or preDescemet stroma is considered optimal because of its superior visual outcomes, particularly immediately after the operation, yet a submaximal dissection can provide better tectonic stability and increased postoperative ECD, while offering similar visual acuity after 6 months [122]. Therefore, a submaximal dissection could be beneficial in eyes with low preoperative ECD. While much of the focus of the controversy of DALK techniques revolves around dissection techniques (manual vs. big bubble), each ap- proach provides its own benefits. Big bubble allows for a quicker dissection and a more regular interface, but a manual dissection provides more control and a lower risk of inadvertent perforation. Specifically, for big bubble, little evidence suggests an optimal localization of the intrastromal air injection, but bubbles generated from the periphery (outside the trephination) are more likely to result in type 2 bubbles and subsequent perforation.

While the consensus suggests a deeper injection depth provides a higher success rate of bubble formation and better postoperative visual outcomes, a shallower starting point decreases risk of perforation [122]. Multiple visual- 
ization techniques have been developed to increase injection depth while also reducing the risk perforation into the anterior chamber, including the air-endothelial reflex, retro-illumination, and use of iOCT, but none of these techniques have been proven to improve the rate of big bubble creation. Nevertheless, approximately $10 \%$ of initial attempts result in failure, but if switched to viscodissection after the failed attempt, half of those attempts can be converted to success, a higher rate than with pneumodissection.

Compared to $\mathrm{PK}$, two of the biggest advantages to DALK are it reduces allograft reaction and increases tectonic stability [122]. However, newer surgeries using isolated BL grafts provide not only nearly absent allograft reaction and normal tectonic stability but also eliminate suture-related complications, reduce antirejection medications and their subsequent complications, and improve native corneal curvature [122]. BL transplantation is an extraocular approach that contains no corneal surface incisions further reducing the risk, postoperative infectious keratitis and epithelial irregularities. BL onlay is a much newer surgery that places the BL graft in its anatomic position on the anterior surface of the cornea and is much less technically challenging than the original inlay technique, while also allowing for keratectomy in the setting of anterior stromal scars [113, 114]. It induces similar flattening to BL inlay transplantation, but long-term results are still pending [113].

\section{Posterior Lamellar Keratoplasty}

\section{Descemet Membrane Endothelial Keratoplasty}

For decades, the only definitive treatment for corneal endothelial dysfunction was PK, removing a huge swath of healthy recipient tissue with the goal of replacing the thin diseased endothelium. However, in the late 1990s, a revolution took place when posterior lamellar keratoplasties became feasible with the discovery that an air bubble could hold a graft in place long enough for it to become adherent to the posterior stroma. DLEK, the first PLK, proved technically challenging and was quickly replaced with DS(A)EK, which excluded the posterior stromal dissection of the recipient cornea. Within the decade, DMEK was introduced and is now emerging as the globally preferred standard of care for patients with corneal endothelial disorders. The operation offers the most anatomic restoration of the operated eye because it features an exact one-to-one replacement of diseased recipient tissue with donor material [123].
Graft preparation using a "no-touch" technique allows for higher ECD and for a single donor cornea to be used in corneal transplants on 2 recipients: one DMEK and one DALK, which can expand the donor pool in regions of tissue scarcity. Moreover, the final steps of graft preparation can be done in the operating room, so the surgeon has the freedom to size the graft appropriate to the operated eye and its pathology. While the surgery itself is performed through a smaller wound ( 3.0 vs. $4.5 \mathrm{~mm}$ ) than DS(A)EK, one of the biggest pushbacks is the perceived difficulty of unfolding the graft. The development of Moutsouris sign or the use of an S-stamp makes the visualization of graft orientation easier and, thus, reduces the risk of upside-down graft implantation [124].

Elimination of the stromal-stromal interface provides a faster and more complete visual recovery compared to its predecessor DS(A)EK; $>98 \%$ of operated eyes achieve best-corrected visual acuities $\geq 20 / 40(0.5)$ within 6 months of surgery, with half of all eyes achieving $\geq 20 / 20$ (1.0) [120]. Visual is stable through at least the first 5 years, with 82 and $54 \%$ maintaining $\geq 20 / 25(0.8)$ and $\geq 20 / 20$ (1.0), respectively. ECD declines sharply (by $37 \%$ ) in the first 6 months but levels off to a slow decline (7\% annually) thereafter [124].

The most common complication of the operation is partial graft detachment, which may occur in 10-20\% of operated eyes, but which is correctable by a "rebubbling" procedure to reattach the dislocated tissue [123]. Additionally, the extent of graft detachment may be the biggest predictor of graft failure: while eyes with fully adherent grafts enjoy a 5 -year survival rate of $95 \%$, eyes with graft detachments $>1 / 3$ of the graft area experience a survival rate of $27 \%(p<0.0001)$. Furthermore, large graft detachments account for $>70 \%$ of the $8.8 \%$ of grafts that require retransplantation in the first 5 years, with primary graft failure accounting for a single retransplantation (0.2\%) [125].

Compared to alternate forms of endothelial keratoplasty, such as DS(A)EK, DMEK offers the most complete and rapid visual rehabilitation, a lower steroid burden, and equal or fewer postoperative complications [120]. In the past decade, efforts have been made to develop procedures to make endothelial keratoplasty easier or reduce (or even eliminate) the risk of allograft reaction postoperatively. The first attempt, Descemet membrane endothelial transfer, showed initial promise but ended in failure when a high rate of eyes developed retrocorneal membrane $[126,127]$. While quarter-DMEK offers similar visual outcomes as DMEK, reduces the steroid burden, and further widens the donor pool, allowing for up to 5 


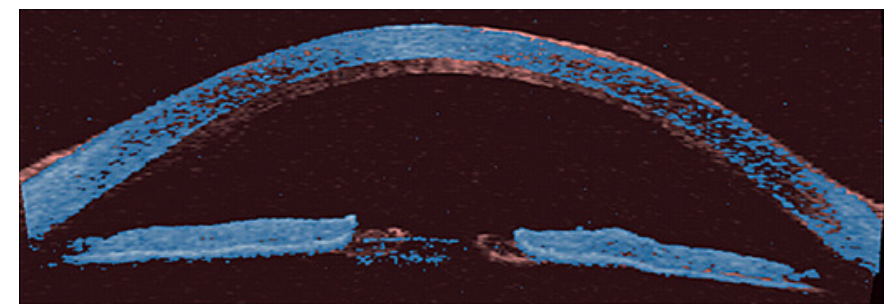

Fig. 4. Overlay of anterior segment OCT images immediately postoperative (red) and at 6 months (blue) after DMEK. Note that the decrease in pachymetry is associated with a steeper posterior corneal curvature and an increase in arc length of the posterior corneal surface (reprinted from Quilendrino et al. [134] with permission). DMEK, Descemet membrane endothelial keratoplasty.

recipients for 1 donor cornea, eyes that underwent quarter-DMEK also experience a higher rate of graft detachment [102, 128]. Descemet stripping only (DSO) with concurrent rho kinase (ROCK) inhibitors provides another option in eyes with mild, central Fuchs dystrophy, and because no donor tissue is transplanted, eliminates the risk of allograft reaction and steroid burden; however, DSO is not effective in eyes with advanced Fuchs dystrophy or bullous keratopathy, and the visual recovery is significantly slower than seen in DMEK [129]. The newest and potentially most promising alternative to DMEK, injected cultured corneal endothelial cells with a ROCK inhibitor, demonstrates rapid corneal clearance and improvement in visual acuity and success even in eyes with bullous keratopathy, but long-term results are still pending [130]. Overall, DMEK remains the gold standard for the treatment of corneal endothelial dysfunction because of its superior outcomes in a wide array of pathology.

\section{Endothelial Cell "Loss" after DMEK}

The early postoperative period after DMEK is characterized by the rapid reduction in measured ECD of the transplanted tissue. Compared to preoperative measurements made of the graft at the eye bank prior to transplantation, a reduction in measured cell density of approximately $35 \%$ is routinely observed in the first 6 months after surgery. Thereafter, the rate of decline appears to slow substantially to approximately $7 \%$ per year, which is maintained through at least 5 years postoperatively [125, 131].

These results are extremely reproducible, with corroborating data from a series of comparable studies examining DMEK performed in "typical" eyes (i.e., for routine indications), as well as DMEK performed for more severe pathologies (i.e., aphakic bullous keratopathy and eyes with ACIOLs). This striking numerical similarity, regardless of DMEK indication and regardless of the surgeon's identity, suggests that the standard precipitous decline in measured cell density immediately following surgery is not related to the surgical technique and instead may be an inherent feature of the operation [132]. Nevertheless, it remains a mystery what exactly accounts for this numerical discrepancy between the cell density measured preoperatively and that measured immediately postoperatively.

After surgical trauma was disqualified as a possible explanation (by the lack of correlation between difficult/ prolonged surgery and cell density decline and by the lack of a "cell density gap" between novice and experienced DMEK surgeons), the first and most obvious candidate theory was endothelial cell migration from the donor tissue out onto adjacent bare areas of the recipient posterior stroma [132]. However, one problem for this theory is that, recently, it has been shown that the precipitous postsurgical decline in measured cell density is evident as early as 1 day postoperatively [133]. Although in vitro endothelial cell migration in quarter-DMEK grafts has been observed as early as 4 days, migration to the extent that would cause significant ECD decline was not observed until 6-14 days; therefore, ECD decline may occur too rapidly for a radical redistribution of cells to realistically occur by migration $[103,104]$.

In 2011, Quilendrino et al. [134] proposed that some of this early measured decline in cell density may be a function of a change in corneal shape. With a fully attached DMEK graft, the surface area of the recipient posterior cornea must expand as the overlying cornea deswells (assuming a stable anterior corneal curvature). This increased surface area must involve the redistribution of endothelial cells over a larger expanse, resulting in reduced cell density measurements without representing a true decline in cell number [134]. Quilendrino et al. [134] proposed that this simple mathematical model for corneal shape change after DMEK may explain as much as $25 \%$ of the total cell density decline measurable immediately postoperatively (Fig. 4). Other potential theories include discrepant measurements between the eye bank in vitro assessment and clinical in vivo photographs as a function of different imaging modalities, and not a true indication of any change in absolute cell number [132].

\section{DMEK in Phakic Eyes}

Cataract surgery is often performed prior to or in conjunction with endothelial keratoplasty, in part because of the high incidence of cataract formation, particularly af- 


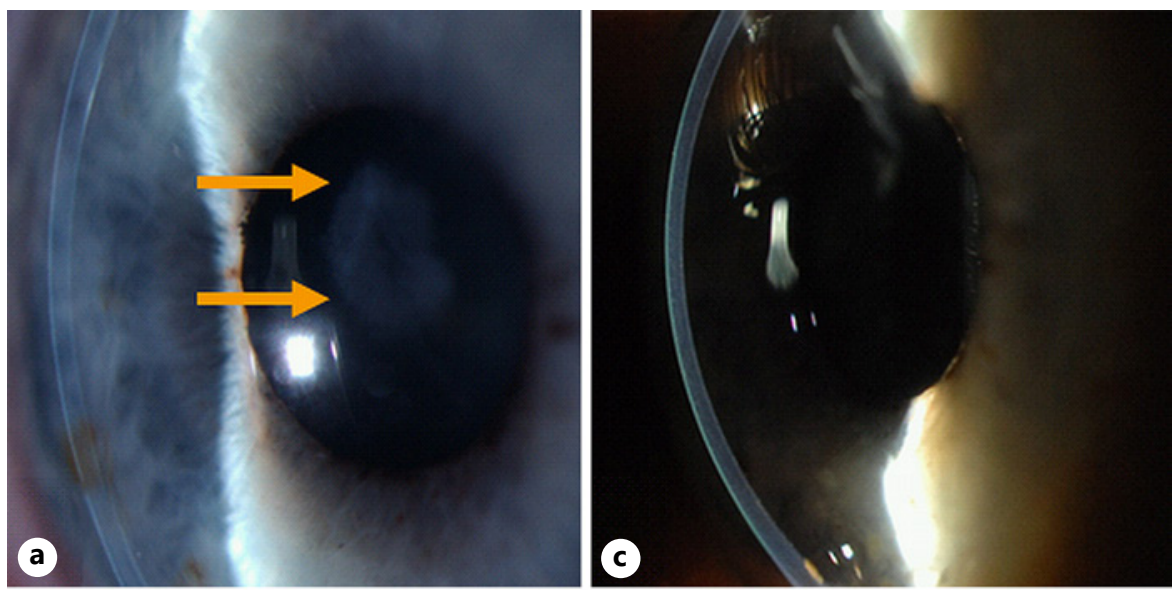

Fig. 5. Eye with an anterior subcapsular cataract after DMEK $(\mathbf{a}, \mathbf{b})$ before cataract surgery. After phacoemulsification, slitlamp images show a clear cornea and IOL (c). Reprinted from Parker et al. [135] with permission. DMEK, Descemet membrane endothelial keratoplasty.

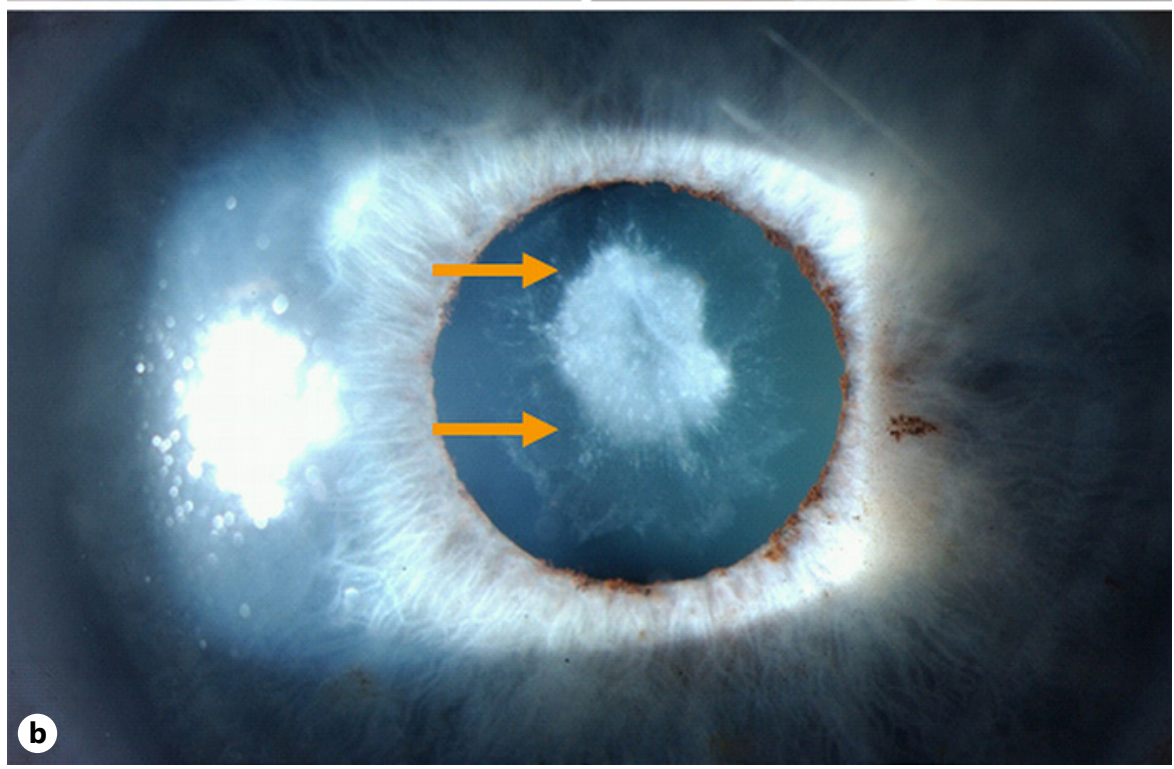

ter DSAEK in phakic eyes (7-37\%) [135]. However, in patients with clear crystalline lenses, there may be some advantages in retaining the natural lens, if possible.

The influence of preoperative lens status on the surgical outcomes of DMEK has remained relatively unknown until recently, and most studies suggest no significant difference in visual outcomes. Compared to an age-matched group of pseudophakic eyes and when controlling for preoperative visual acuity, phakic eyes achieved equal average postoperative best-corrected visual acuity, but a higher percentage of $>20 / 20$ (1.0) results, possibly owing to some optical advantage in preserving the natural lens [136].

While approximately $10 \%$ of phakic eyes undergoing DMEK experience temporary angle-closure glaucoma caused by transient pupillary blockade from the air bubble slipping behind the iris with evidence of mild glaukom- flecken postoperatively, only $4 \%$ of operated eyes developed a cataract, but more recent studies say that the rate may be $<2 \%$ [136]. Other postoperative metrics including ECD, central corneal thickness, and (partial) graft detachment were not significantly different between phakic and pseudophakic eyes receiving DMEK [136-138].

When compared to eyes undergoing combined cataract surgery and DMEK, eyes undergoing phakic DMEK may have a lower rate of graft detachment, but all other outcomes were similar [139]. Phakic DMEK may therefore be a safe and reasonable option for patients with isolated endothelial dysfunction and clear crystalline lenses, avoiding increased postoperative complications while allowing for optimal visual outcomes and retention of accommodation in young patients (Fig. 5).

In eyes with both cataract and visually significant Fuchs dystrophy, combination of DMEK with phaco- 
emulsification may be appropriate. However, it is also reasonable to perform phakic DMEK first and then cataract surgery later, in a staged operation, to potentially improve the accuracy of lens calculations which may be affected by the transplant.

\section{Discussion}

Today, PK and its cousin DALK remain the standard of care for eyes with advanced $\mathrm{KC}$ once visual acuity becomes unacceptable and/or CTL intolerance develops $[140,141]$. And, while the outcomes of these operations are often described as "good," many unresolved challenges remain $[142,143]$.

Specifically, many recipients of both surgeries are young at the time of their operations, in some cases extremely so, rendering the procedures more technically challenging and the postoperative care more difficult, especially if there is some coexisting cognitive or behavioral limitation (which is not altogether uncommon) [144147]. Young eyes also tend to be phakic: in the first few years after transplantation, cataracts may develop. As a result, lens extraction may be necessary, potentially risking the graft's health in the process $[148,149]$. Children already suffer poorer graft survival than adults, but even if the statistics were identical, still it is very likely that young patients will "outlive" their first transplant and therefore require reoperation(s) [11]. And, because the outcomes of second and third transplants tend to be inferior to the first, many patients who seem - initially - to do well with both surgeries may, ultimately, experience problems [12]. This is especially true given that advanced $\mathrm{KC}$ is found in patients with severe ocular surface disorders, many of which are exacerbated by PK/DALK and their large incisions, sutures, and the neurotrophic corneas they produce [13, 14]. Beneath the ocular surface, additional wound healing problems may also be found, since the stroma at the junction between the graft and the recipient probably never securely heals, predisposing these eyes to inadvertent traumatic rupture and ongoing ectasia at the tissue interface (and thereby "recurrence" of their disease) [15].

All of these difficulties are fundamental problems intrinsic to DALK and PK themselves and therefore not likely to be cured by refinements to operative technique or instrumentation. The solution may instead require an entirely new surgical approach, possibly one that abandons the idea of exchanging or replacing the recipient cornea with donor tissue. To this end, recently, there has been a strong push to intervene early against eyes with mild $\mathrm{KC}$ in the hopes of arresting progression before $\mathrm{PK}$ or DALK (and their attendant complications) becomes necessary. Both UVCXL and ICRS implantation have been evaluated for this purpose, each with demonstrated success. Nevertheless, many eyes are not candidates for either operation. Those with corneas steeper than $58 \mathrm{di}$ opters (D) or thinner than $400 \mu \mathrm{m}$, for example, may be ineligible for both ICRS and UVCXL according to published safety guidelines [16, 17]. Further, in the USA, ICRS is not approved in patients younger than 18 years old, and UVCXL - while recently FDA approved - is becoming more commonly offered but may still be difficult to obtain for patients without insurance coverage $[16,17]$.

Other exclusions also apply: corneas with prior herpetic disease are disqualified from UVCXL, and a history of recurrent erosions excludes ICRS placement $[16,17]$. Overall, it may be fair to say that, for various reasons, many patients with "active" or "ongoing" KC are ineligible for these therapies and therefore may continue to progress [18]. Eventually, CTL intolerance might develop. Many patients then receive either PK or DALK and be subjected to possible complications.

What has been badly needed is an operation to arrest keratoconic progression in eyes poorly suited for UVCXL or ICRS implantation, before PK or DALK becomes necessary [18-20]. For this reason, in 2014, BL inlay transplantation was introduced with the theory of replacing the pathologically fragmented BL, which critically destabilizes a keratoconic cornea, predisposing it to ectasia [21]. The first cohort of patients was limited to those with advanced $\mathrm{KC}$ (preoperative $K_{\max }>70 \mathrm{D}$ ), and while the recipient corneas were flattened by an average of 8-9 D and disease progression was halted, average spectacle and CTL visual acuities did not significantly change. The patients, however, did report improvement in CTL tolerance [21].

Since BL transplantation has been introduced, the technique has expanded to the USA, and longer-term results have demonstrated that the ectasia in most eyes ceases to progress, and the average spectacle-corrected visual acuity shows modest improvement with no documented postoperative complications in the surgery's history, which is in stark contrast with the keratoplasties that BL transplantation is used to prevent [109-112]. While this technique is an option to effectively halt the progression in eyes with advanced $\mathrm{KC}$, one of its major pushbacks is the difficulty of the operation [112]. Some modifications to the surgery, such as use of a femtosecond laser to create the midstromal pocket, have been developed with at least some success, but new surgeries, such as BL onlay transplantation and CAIRS implantation, may be 
more technically feasible while still being equally as effective at flattening corneal curvature, halting disease progression, and preventing full or near-full thickness corneal transplantation.

Meanwhile, for corneal endothelial disorders, several different techniques have been in existence, and DMEK may have superseded its predecessor DSAEK as the procedure of choice for this condition [26]. With a graft consisting exclusively of an isolated DM and its attendant endothelium, DMEK effects a one-to-one replacement of the donor for diseased tissue, resulting in the near complete anatomic restoration of the recipient cornea [26].

Immediately, postoperatively, the measured ECD of a DMEK graft displays a sharp decline, consistently measured at approximately $35 \%$ of the preoperative value [27, 28]. Although this decline is frequently expressed as "cell loss" resulting from intraoperative tissue manipulation, this explanation may be overly simplistic, and other factors may also be involved, for example: cell migration/ redistribution from the graft onto surrounding areas of the recipient posterior stroma [29]. Nevertheless, by 6 months after surgery, the rate of cell density decline appears to stabilize at a low level (around 5\% per year). This pattern closely resembles that seen after DS(A)EK and differs from the cell density trends seen after DLEK and $\mathrm{PK}$, which both show an indefinite, linear decline in cell density in perpetuity [30-32].

Average BCVA after DMEK is $20 / 25$ (0.8), which is usually achieved by 3 months postoperatively and with little entailed hyperopic shift [33]. This contrasts with the average visual acuities, recovery times, and refractive shifts after both PK and DS(A)EK: after PK, BCVA averages only $20 / 40(0.5)$, is delayed by 1 year, and commonly entails severe astigmatism; after DS(A)EK, BCVA averages 20/30, is delayed by 6 months, and entails twice as much hyperopic shift as DMEK [34]. However, DMEK's visual results are limited by the condition of the anterior corneal surface and by the lens status of the recipient eye. Specifically, longstanding corneal edema may produce anterior stromal scarring/fibrosis, which may not entirely resolve after DMEK [35]. Therefore, early endothelial replacement before these changes develop may be advisable (otherwise, CTL fitting may mitigate some of these abnormalities). In addition, while phakic and pseudophakic patients seem to achieve the same average visual results after surgery, the "extremes" of good vision are more commonly found in phakic eyes, suggesting some optical advantage in preserving the natural lens [36]. Unlike phakic eyes undergoing DS(A)EK, cataract formation is not the rule after DMEK, possibly as a result of the lower post- operative steroid burden entailed. In our series, only $4 \%$ of phakic eyes undergoing DMEK required subsequent phacoemulsification within a 2 -year follow-up period [36]. However, phakic eyes receiving DMEK do display a unique susceptibility to air bubble-induced angle-closure glaucoma, in which the air fill left postoperatively pushes against the lens, which responds by tilting forward and closing off the trabecular meshwork [37]. To prevent this occurrence, phakic eyes are best left with a smaller air fill at the conclusion of their operation: only $50 \%$ of the volume of the anterior chamber, rather than $75 \%$, as recommended in pseudophakic eyes. Interestingly, phakic eyes treated in this manner do not seem to display a higher percentage of postoperative graft detachments than their pseudophakic counterparts, suggesting that the postoperative air fill may be less critical to graft adherence than is currently believed [36].

Because DS(A)EK involves a stroma-stroma interface at the junction of donor and recipient tissues and because this interface may be highly reflective and irregular, the optical quality of the transplanted eye may suffer. Other reasons for poor visual acuity after DS(A)EK include the following: stromal "waves" in the donor lenticule stemming from a curvature mismatch between the recipient's cornea and the graft and recipient DM "remnants" left in the interface. As a result of these 3 factors, some eyes which receive an uncomplicated DS(A)EK operation, experience a normal postoperative course, and present with clear and well-attached grafts may, nevertheless, achieve unsatisfying visual results [38]. Reoperating on these eyes to replace their DS(A)EK grafts with DMEKs has been shown to result in substantial visual improvements in these cases, likely because DMEK grafts - being devoid of stroma - fit better against the recipient posterior cornea and induce less scarring. Moreover, separate studies have independently demonstrated that - when operated with both techniques - patients subjectively prefer the vision in their DMEK eye [39]. Altogether, these results confirm the underlying philosophy of DMEK surgery that the operation returns the eye to a nearly normal anatomy, unlike PK, DLEK, and even DS(A)EK [40].

More recently, efforts have been made to increase the donor pool by creating multiple grafts from a single donor cornea. Hemi-DMEK and quarter-DMEK offer similar short- and intermediate-term visual outcomes as conventional DMEK, but both operations have a higher rate of partial graft detachment and have prolonged times to peripheral corneal clearance [100-103]. DSO eliminates donor tissue - and therefore the risk of allograft reaction altogether, but the interval to visual recovery, even with 
the combined use of a ROCK inhibitor, is much longer than with a graft [129]. The newest and the most promising innovation on the horizon of treatments for corneal endothelial dysfunction is endothelial regeneration: the use of injectable cultured corneal endothelial cells [130]. When injected intracamerally with a ROCK inhibitor, preliminary results of cultured human allogenic corneal endothelial cells from the singular human trial rival visual acuity and ECD outcomes of conventional DMEK [130]. While this technique must demonstrate long-term effectiveness and overcome significant regulatory hurdles, corneal endothelial regeneration may indeed be the technology to challenge DMEK as the gold standard for treatment of corneal endothelial dysfunction. We may proceed with injection of cultured corneal endothelial cells, potentially advancing to the use of autologous cells, trailblazing the way to eventually a "keratoplasty-free" world that totally abandons the concepts of donor material altogether.

\section{Conclusion}

The past 2 decades have seen an explosion of new keratoplasty techniques, a historically unparalleled flurry of activity which, ironically, may be superseded in the near future by the complete end of "keratoplasty" as a concept. Corneal grafts have steadily gotten smaller, thinner, and more peculiar. This applies to both transplants for the anterior and the posterior corneal surfaces.

The logic motivating these innovations has been consistent: minimally invasive substitutions are to be preferred over wholesale replacements of corneal tissue. As new, tailored, lamellar operations have grown in popularity worldwide, we may be approaching a point where "transplantation" itself becomes unnecessary. Already, successful reports of DSO treatments for patients with mild central Fuchs dystrophy are accumulating, and in Japan, promising results with injectable endothelial cells are likewise emerging. The concept sticks that replacing a dysfunctional endothelial layer with a similarly positioned donor graft may be unnecessary and that we might achieve the desired effect in a simpler and safer manner by some other intervention. If so, then this would mean that "keratoplasty" as a technique may soon be finished, at least for endothelial surgeries.

For disorders of the anterior cornea, the introduction of UVCXL and ICRS implantation has already cut heavily into the number of transplants being performed, and BL transplantation, both inlay and onlay techniques, and CAIRS implantation may continue this trend away from
PK and DALK. As a result, this may be simultaneously the most exciting - and possibly uncertain - time in history to be a corneal surgeon. And, despite all the foregoing speculation about the future of corneal transplantation, it could also be some unforeseen advance that carries the profession forward.

\section{Conflict of Interest Statement}

No author has a financial or proprietary interest in any material or method mentioned.

\section{Funding Sources}

No funding was received to support this research.

\section{Author Contributions}

Jack Parker, MD PhD: concept and design of the work; acquisition, analysis, and interpretation of data; drafting and revising the manuscript; final approval to be published; agrees be accountable for all aspects of the work in ensuring that questions related to the accuracy or integrity of any part of the work are appropriately investigated and resolved. Philip Dockery, MD MPH: acquisition, analysis, and interpretation of data; drafting and revising the manuscript; final approval to be published; agrees be accountable for all aspects of the work in ensuring that questions related to the accuracy or integrity of any part of the work are appropriately investigated and resolved. Ana Preda-Naumescu, BS: acquisition of data; revising the manuscript; final approval to be published; agrees be accountable for all aspects of the work in ensuring that questions related to the accuracy or integrity of any part of the work are appropriately investigated and resolved. Martine Jager, MD PhD: concept and design of the work; drafting and revising the manuscript; final approval to be published; agrees be accountable for all aspects of the work in ensuring that questions related to the accuracy or integrity of any part of the work are appropriately investigated and resolved. Korine van Dijk, $\mathrm{PhD}$ : concept and design of the work; acquisition, analysis, and interpretation of data; drafting and revising the manuscript; final approval to be published; agrees be accountable for all aspects of the work in ensuring that questions related to the accuracy or integrity of any part of the work are appropriately investigated and resolved. Isabel Dapena, $\mathrm{MD} \mathrm{PhD}$ : concept and design of the work; interpretation of data; drafting and revising the manuscript; final approval to be published; agrees be accountable for all aspects of the work in ensuring that questions related to the accuracy or integrity of any part of the work are appropriately investigated and resolved. Gerrit Melles, MD PhD: concept and design of the work; interpretation of data; drafting and revising the manuscript; final approval to be published; agrees be accountable for all aspects of the work in ensuring that questions related to the accuracy or integrity of any part of the work are appropriately investigated and resolved. 


\section{References}

1 Sabet S, Adamopoulou A. Basic structure and function of the human cornea and adnexal structures. In: Copeland R, Afshari N, editors. Copeland Afshari's principles and practice of cornea. Jaypee Brothers Medical Publishers; 2013.

2 Qazi Y, Hamrah P. Corneal allograft rejection: immunopathogenesis to therapeutics. J Clin Cell Immunol. 2013 Nov 20;2013(Suppl 9):006.

3 Maurice D. The location of the fluid pump in the cornea. J Physiol. 1972;221(1):43-54.

4 Hodson S, Miller F. The bicarbonate ion pump in the endothelium which regulates the hydration of rabbit cornea. J Physiol. 1976; 263(3):563-77.

5 Daniels JT, Harris AR, Mason C. Corneal epithelial stem cells in health and disease. Stem Cell Rev. 2006;2(3):247-54.

6 Maurice DM. The cornea and sclera. In: Davidson $\mathrm{H}$, editor. The eye. New York: Academic Press; 1984.

7 Germundsson J, Karanis G, Fagerholm P, Lagali N. Age-related thinning of Bowman's layer in the human cornea in vivo. Invest Ophthalmol Vis Sci. 2013;54(9):6143-9.

8 Gordon MK, Foley JW, Birk DE, Fitch JM, Linsenmayer TF. Type V collagen and Bowman's membrane. Quantitation of mRNA in corneal epithelium and stroma. J Biol Chem. 1994;269(40):24959-66.

9 Nakayasu K, Tanaka M, Konomi H, Hayashi T. Distribution of types I, II, III, IV and V collagen in normal and keratoconus corneas. Ophthalmic Res. 1986;18(1):1-10.

10 Holmberg K. The fine structure of Bowman's layer and the basement membrane of the corneal epithelium. Am J Ophthalmol. 1960;50: 1013-21.

11 Netto MV, Mohan RR, Sinha S, Sharma A, Dupps W, Wilson SE. Stromal haze, myofibroblasts, and surface irregularity after PRK. Exp Eye Res. 2006;82(5):788-97.

12 Møller-Pedersen T. On the structural origin of refractive instability and corneal haze after excimer laser keratectomy for myopia. Acta Ophthalmol Scand Suppl. 2003;237(237):1-20.

13 Lagali N, Germundsson J, Fagerholm P. The role of Bowman's layer in corneal regeneration after phototherapeutic keratectomy: a prospective study using in vivo confocal microscopy. Invest Ophthalmol Vis Sci. 2009; 50(9):4192-8.

14 Lie J, Droutsas K, Ham L, Dapena I, Ververs $\mathrm{B}$, Otten $\mathrm{H}$, et al. Isolated Bowman layer transplantation to manage persistent subepithelial haze after excimer laser surface ablation. J Cataract Refract Surg. 2010;36(6):1036-41.

15 Sykakis E, Carley F, Irion L, Denton J, Hillarby MC. An in depth analysis of histopathological characteristics found in keratoconus. Pathology. 2012;44(3):234-9.

16 Zimmermann DR, Fischer RW, Winterhalter KH, Witmer R, Vaughan L. Comparative studies of collagens in normal and keratoconus corneas. Exp Eye Res. 1988;46(3):431-42.
17 Dawson DG, Grossniklaus HE, McCarey BE, Edelhauser HF. Biomechanical and wound healing characteristics of corneas after excimer laser keratorefractive surgery: is there a difference between advanced surface ablation and sub-Bowman's keratomileusis? J Refract Surg. 2008;24(1):S90-6.

18 Groeneveld-van Beek EA, Parker J, Lie JT, Bourgonje V, Ham L, van Dijk K, et al. Donor tissue preparation for Bowman layer transplantation. Cornea. 2016 Jun 29;35(12):1499. Epub ahead of print.

19 McKee HD, Irion LC, Carley FM, Jhanji V, Brahma AK. Residual corneal stroma in bigbubble deep anterior lamellar keratoplasty: a histological study in eye-bank corneas. Br J Ophthalmol. 2011;95(10):1463-5.

20 Dua HS, Faraj LA, Said DG, Gray T, Lowe J. Human corneal anatomy redefined: a novel pre-Descemet's layer (Dua's layer). Ophthalmology. 2013;120(9):1778-85.

21 Schlötzer-Schrehardt U, Bachmann BO, Tourtas T, Torricelli AA, Singh A, González $\mathrm{S}$, et al. Ultrastructure of the posterior corneal stroma. Ophthalmology. 2015;122(4):693-9.

22 McKee HD, Irion LC, Carley FM, Brahma AK, Jafarinasab MR, Rahmati-Kamel M, et al. Re: Dua et al.: human corneal anatomy redefined: a novel pre-Descemet layer (Dua's layer) 715 (Ophthalmology 2013; 120: 1778-85). Ophthalmology. 2014; 121(5):e24-5.

23 Dua HS, Mastropasqua L, Faraj L, Nubile M, Elalfy MS, Lanzini M, et al. Big bubble deep anterior lamellar keratoplasty: the collagen layer in the wall of the big bubble is unique. Acta Ophthalmol. 2015;93(5):427-30.

24 Agarwal A, Dua HS, Narang P, Kumar DA, Agarwal A, Jacob S, et al. Pre-Descemet's endothelial keratoplasty (PDEK). Br J Ophthalmol. 2014;98(9):1181-5.

25 Dua HS, Termote K, Kenawy MB, Said DG, Jayaswal R, Nubile M, et al. Scrolling characteristics of pre-Descemet endothelial keratoplasty tissue: an ex vivo study. Am J Ophthalmol. 2016;166:84-90.

26 Agarwal A, Agarwal A, Narang P, Kumar DA, Jacob S. Pre-Descemet endothelial keratoplasty with infant donor corneas: a prospective analysis. Cornea. 2015;34(8):859-65.

27 Dua HS, Said DG. Pre-Descemets endothelial keratoplasty: the PDEK clamp for successful PDEK. Eye. 2017 Feb 17;31(7):1106. Epub ahead of print.

28 Dua HS, Said DG. Clinical evidence of the pre-Descemets layer (Dua's layer) in corneal pathology. Eye. 2016;30(8):1144-5.

29 Johnson DH, Bourne WM, Campbell RJ. The ultrastructure of Descemet's membrane. I. Changes with age in normal corneas. Arch Ophthalmol. 1982;100(12):1942-7.

30 Bourne WM, Johnson DH, Campbell RJ. The ultrastructure of Descemet's membrane. III. Fuchs' dystrophy. Arch Ophthalmol. 1982; 100(12):1952-5.
31 Lie JT, Birbal R, Ham L, van der Wees J, Melles GR. Donor tissue preparation for Descemet membrane endothelial keratoplasty. J Cataract Refract Surg. 2008;34(9):1578-83.

32 Groeneveld-van Beek EA, Lie JT, van der Wees J, Bruinsma M, Melles GR. Standardized 'no-touch' donor tissue preparation for DALK and DMEK: harvesting undamaged anterior and posterior transplants from the same donor cornea. Acta Ophthalmol. 2013; 91(2):145-50.

33 McCarey BE, Edelhauser HF, Lynn MJ. Review of corneal endothelial specular microscopy for FDA clinical trials of refractive procedures, surgical devices, and new intraocular drugs and solutions. Cornea. 2008;27(1):116.

34 Laule A, Cable MK, Hoffman CE, Hanna C. Endothelial cell population changes of human cornea during life. Arch Ophthalmol. 1978; 96(11):2031-5

35 Capella JA. Regeneration of endothelium in diseased and injured corneas. Am J Ophthalmol. 1972;74(5):810-7.

36 Ikebe H, Takamatsu T, Itoi M, Fujita S Changes in nuclear DNA content and cell size of injured human corneal endothelium. Exp Eye Res. 1988;47(2):205-15.

37 Sturrock GD, Sherrard ES, Rice NS. Specular microscopy of the corneal endothelium. Br J Ophthalmol. 1978;62(12):809-14.

38 Joyce NC. Proliferative capacity of the corneal endothelium. Prog Retin Eye Res. 2003; 22(3):359-89.

39 Joyce NC, Harris DL, Mello DM. Mechanisms of mitotic inhibition in corneal endothelium: contact inhibition and TGF-beta2. Invest Ophthalmol Vis Sci. 2002;43(7):2152-9.

40 Amann J, Holley GP, Lee SB, Edelhauser HF. Increased endothelial cell density in the paracentral and peripheral regions of the human cornea. Am J Ophthalmol. 2003;135(5):58490.

41 Konomi K, Zhu C, Harris D, Joyce NC. Comparison of the proliferative capacity of human corneal endothelial cells from the central and peripheral areas. Invest Ophthalmol Vis Sci. 2005;46(11):4086-91.

42 Baum JL, Niedra R, Davis C, Yue BY. Mass culture of human corneal endothelial cells. Arch Ophthalmol. 1979;97(6):1136-40.

43 Sumide T, Nishida K, Yamato M, Ide T, Hayashida Y, Watanabe K, et al. Functional human corneal endothelial cell sheets harvested from temperature-responsive culture surfaces. FASEB J. 2006;20(2):392-4.

44 Slettedal JK, Lyberg T, Røger M, Beraki K, Ramstad H, Nicolaissen B. Regeneration with proliferation of the endothelium of cultured human donor corneas with extended postmortem time. Cornea. 2008;27(2):212-9.

45 Senoo T, Joyce NC. Cell cycle kinetics in corneal endothelium from old and young donors. Invest Ophthalmol Vis Sci. 2000;41(3): 660-7. 
46 Senoo T, Obara Y, Joyce NC. EDTA: a promoter of proliferation in human corneal endothelium. Invest Ophthalmol Vis Sci. 2000; 41(10):2930-5.

47 Wilson SE, Weng J, Blair S, He YG, Lloyd S. Expression of E6/E7 or SV40 large T antigencoding oncogenes in human corneal endothelial cells indicates regulated high-proliferative capacity. Invest Ophthalmol Vis Sci. 1995; 36(1):32-40.

48 Schonthal AH, Hwang JJ, Stevenson D, Trousdale MD. Expression and activity of cell cycle-regulatory proteins in normal and transformed corneal endothelial cells. Exp Eye Res. 1999;68:531-9. Chinese.

49 Shao Y, Hu D, Chen J. [A study on effect of bFGF, EGF and NGF on growth of cultured human corneal endothelial cells]. Yan Ke Xue Bao. 2008;24(1):9-12.

50 Blake DA, Yu H, Young DL, Caldwell DR. Matrix stimulates the proliferation of human corneal endothelial cells in culture. Invest Ophthalmol Vis Sci. 1997;38(6):1119-29.

51 Miyata K, Drake J, Osakabe Y, Hosokawa Y, Hwang D, Soya K, et al. Effect of donor age on morphologic variation of cultured human corneal endothelial cells. Cornea. 2001;20(1): 59-63.

52 Beckman KB, Ames BN. The free radical theory of aging matures. Physiol Rev. 1998;78(2): $547-81$.

53 Joyce NC, Navon SE, Roy S, Zieske JD. Expression of cell cycle-associated proteins in human and rabbit corneal endothelium in situ. Invest Ophthalmol Vis Sci. 1996;37(8): 1566-75.

54 Joyce NC. Cell cycle status in human corneal endothelium. Exp Eye Res. 2005;81(6):62938.

55 Hassell JR, Birk DE. The molecular basis of corneal transparency. Exp Eye Res. 2010; 91(3):326-35.

56 Maurice DM. The structure and transparency of the cornea. J Physiol. 1957;136(2):26386.

57 Hart RW, Farrell RA. Light scattering in the cornea. J Opt Soc Am. 1969;59(6):766-74.

58 Jester JV, Moller-Pedersen T, Huang J, Sax CM, Kays WT, Cavangh HD, et al. The cellular basis of corneal transparency: evidence for 'corneal crystallins'. J Cell Sci. 1999;112: 613-22.

59 Fischbarg J, Maurice DM. An update on corneal hydration control. Exp Eye Res. 2004; 78(3):537-41.

60 Meek KM, Leonard DW, Connon CJ, Dennis S, Khan S. Transparency, swelling and scarring in the corneal stroma. Eye. 2003;17(8): 927-36.

61 Hart WM. The cornea. In: Adler's physiology of the eye. 9th ed. St. Louis: Moby-Year Book; 1992. Vol. 3; p. 55-8.

62 Noske W, Fromm M, Levarlet B, Kreusel KM, Hirsch M. Tight junctions of the human corneal endothelium: morphological and electrophysiological features. Ger J Ophthalmol. 1994;3(4-5):253-7.
63 Bonanno JA. Identity and regulation of ion transport mechanisms in the corneal endothelium. Prog Retin Eye Res. 2003;22(1):69-94.

64 Fischbarg J. Active and passive properties of the rabbit corneal endothelium. Exp Eye Res. 1973; 15(5):615-38.

65 Huff JW, Green K. Demonstration of active sodium transport across the isolated rabbit corneal endothelium. Curr Eye Res. 1981; $1(2): 113-4$.

66 Lim JJ. Na+ transport across the rabbit corneal endothelium. Curr Eye Res. 1981;1(4): 255-8.

67 Whikehart DR, Soppet DR. Activities of transport enzymes located in the plasma membranes of corneal endothelial cells. Invest Ophthalmol Vis Sci. 1981;21(6):819-25.

68 Jentsch TJ, Keller SK, Wiederholt M. Ion transport mechanisms in cultured bovine corneal endothelial cells. Curr Eye Res. 1985; 4(4):361-9.

69 Sun XC, Li J, Cui M, Bonanno JA. Role of carbonic anhydrase IV in corneal endothelial HCO3- transport. Invest Ophthalmol Vis Sci. 2008;49(3):1048-55

70 Fischbarg J. Mechanism of fluid transport across corneal endothelium and other epithelial layers: a possible explanation based on cyclic cell volume regulatory changes. $\mathrm{Br} J \mathrm{Oph}-$ thalmol. 1997;81(1):85-9.

71 Williams KA, Muehlberg SM, Lewis RF, Coster DI. How successful is corneal transplantation? A report from the Australian Corneal Graft Register. Eye. 1995;9(Pt 2):219-27.

72 Soong $\mathrm{MDH}$. Corneal transplantation. In: Spaeth G, editor. Ophthalmic surgery: principles and practice. Philadelphia: Elsevier; 2003. p. 139-60.

73 Power H: IV International congress of ophthalmology. London; 1872. Vol. IV; p. 172.

74 Zirm EK. Eine erfolgreiche totale Keratoplastik. V. Graefes Arch Ophthalmol. 1906; 64:580-93.

75 Filatov VP, Sitchevska O. Transplantation of the cornea. Arch Ophthalmol. 1935;13(3): $321-47$.

76 Murube J. Ramon Castroviejo centenary: a life dedicated to corneal transplantation. Surv Ophthalmol. 2005;50(2):215-25.

77 Vajpayee RB. Corneal transplantation. 1st ed. New Delhi: 2002. p. 3-5.

78 Paton D. The founder of the first eye bank: R. Townley Paton, MD. Refract Corneal Surg. 1991;7(2):190-5.

79 Maurice DM. A scanning slit optical microscopy. Invest Ophthalmol Vis Sci. 1974;13: $1033-7$.

80 Lindstrom RL. Advances in corneal preservation. Trans Am Ophthalmol Soc. 1990;88: 555-648.

81 Terry MA. Endothelial keratoplasty: why aren't we all doing Descemet membrane endothelial keratoplasty? Cornea. 2012;31(5): 469-71.

82 Price MO, Price FW Jr. Endothelial keratoplasty: a review. Clin Experiment Ophthalmol. 2010;38(2):128-40.
83 Barraquer JI. Lamellar keratoplasty. (Special techniques). Ann Ophthalmol. 1972;4(6): 437-69.

84 Tillett CW. Posterior lamellar keratoplasty. Am J Ophthalmol. 1956;41(3):530-3.

85 Culbertson WW. Endothelial replacement: flap approach. Ophthalmol Clin North Am. 2003;16(1):113-8, vii.

86 Archila EA. Deep lamellar keratoplasty dissection of host tissue with intrastromal air injection. Cornea. 1984-1985;3(3):217-8.

87 Anwar M, Teichmann KD. Big-bubble technique to bare Descemet's membrane in anterior lamellar keratoplasty. J Cataract Refract Surg. 2002;28(3):398-403.

88 Melles GR, Remeijer L, Geerards AJ, Beekhuis WH. A quick surgical technique for deep, anterior lamellar keratoplasty using visco-dissection. Cornea. 2000;19(4):427-32.

89 Melles GR, Rietveld FJ, Beekhuis WH, Binder PS. A technique to visualize corneal incision and lamellar dissection depth during surgery. Cornea. 1999;18(1):80-6.

90 Melles GR, Eggink FA, Lander F, Pels E, Rietveld FJ, Beekhuis WH, et al. A surgical technique for posterior lamellar keratoplasty. Cornea. 1998;17(6):618-26.

91 Terry MA, Ousley PJ. Deep lamellar endothelial keratoplasty in the first United States patients: early clinical results. Cornea. 2001;20: 239-43.

92 Melles GR, Lander F, Nieuwendaal C. Sutureless, posterior lamellar keratoplasty: a case report of a modified technique. Cornea. 2002 21(3):325-7.

93 Gorovoy MS. Descemet-stripping automated endothelial keratoplasty. Cornea. 2006;25(8): 886-9.

94 Dirisamer M, Parker J, Naveiras M, Liarakos VS, Ham L, van Dijk K, et al. Identifying causes for poor visual outcome after DSEK/ DSAEK following secondary DMEK in the same eye. Acta Ophthalmol. 2013;91(2):1319.

95 Melles GR, Ong TS, Ververs B, van der Wees J. Descemet membrane endothelial keratoplasty (DMEK). Cornea. 2006;25(8): 987-90.

96 Livny E, Parker JS, van der Kaaij M, Haasdijk ED, van der Wees J, Bruinsma M, et al. Postmortem ultrastructural analysis of a cornea transplanted with Descemet membrane endothelial keratoplasty. Cornea. 2014;33(8): 790-4.

97 Price FW Jr, Price MO. Evolution of endothelial keratoplasty. Cornea. 2013;32(Suppl 1): S28-32.

98 Dapena I, Ham L, Melles GR. Endothelial keratoplasty: DSEK/DSAEK or DMEK: the thinner the better? Curr Opin Ophthalmol. 2009; 20(4):299-307.

99 Lam FC, Baydoun L, Dirisamer M, Lie J, Dapena I, Melles GR. Hemi-Descemet membrane endothelial keratoplasty transplantation: a potential method for increasingthe pool of endothelial graft tissue. JAMA Ophthalmol. 2014;132:1469-73. 
100 Gerber-Hollbach N, Parker J, Baydoun L, Liarakos VS, Ham L, Dapena I, et al. Preliminary outcome of hemi-Descemet membrane endothelial keratoplasty for Fuchs endothelial dystrophy. Br J Ophthalmol. 2016 Feb 2; 100(11):1564. Epub ahead of print.

101 Lam FC, Baydoun L, Satué M, Dirisamer M, Ham L, Melles GR. One year outcome of hemi-Descemet membrane endothelial keratoplasty. Graefes Arch Clin Exp Ophthalmol. 2015;253(11):1955-8.

102 Zygoura V, Baydoun L, Ham L, Bourgonje VJ, van Dijk K, Lie JT, et al. Quarter-Descemet membrane endothelial keratoplasty (quarter-DMEK) for Fuchs endothelial dystrophy: 6 months clinical outcome. $\mathrm{Br} \mathrm{J}$ Ophthalmol. 2018;102(10):1425-30.

103 Miron A, Spinozzi D, Ní Dhubhghaill S, Lie JT, Oellerich S, Melles GRJ, et al. In vitro endothelial cell migration from limbal edgemodified quarter-DMEK grafts. PLoS One. 2019;14(11):e0225462.

104 Miron A, Spinozzi D, Bruinsma M, Lie JT, Birbal RS, Baydoun L, et al. Asymmetrical endothelial cell migration from in vitro Quarter-Descemet membrane endothelial keratoplasty grafts. Acta Ophthalmol. 2018; 96(8):828-33.

105 Dirisamer M, Ham L, Dapena I, van Dijk K, Melles GR. Descemet membrane endothelial transfer: "free-floating" donor Descemet implantation as a potential alternative to "keratoplasty". Cornea. 2012;31:194-7.

106 Lam FC, Bruinsma M, Melles GR. Descemet membrane endothelial transfer. Curr Opin Ophthalmol. 2014;25(4):353-7.

107 Studeny P, Farkas A, Vokrojova M, Liskova $\mathrm{P}$, Jirsova K. Descemet membrane endothelial keratoplasty with a stromal rim (DMEKS). Br J Ophthalmol. 2010;94(7):909-14.

108 Agarwal A, Dua HS, Narang P, Kumar DA, Agarwal A, Jacob S, et al. Pre-Descemet's endothelial keratoplasty (PDEK). Br J Ophthalmol. 2014 Sep;98(9):1181-5.

109 Van Dijk K, Parker J, Tong CM, Ham L, Lie JT, Groeneveld-van Beek EA, et al. Midstromal isolated bowman layer graft for reduction of advanced keratoconus. JAMA Ophthalmol. 2014;132(4):495-501.

110 Van Dijk K, Liarakos VS, Parker J, Ham L, Lie JT, Groeneveld-van Beek EA, et al. Bowman layer transplantation to reduce and stabilize progressive, advanced keratoconus. Ophthalmology. 2015;122(5):909-17.

111 Parker JS, van Dijk K, Melles GR. Treatment options for advanced keratoconus: a review. Surv Ophthalmol. 2015;60(5):459-80.

112 Garcia de Oteyza G, Gonzalez Dibildox LA, Vasquez Romo KA, Tapia-Vasquez A, Davila-Alquisiras JH, Martinez-Baez BE, et al. Bowman layer transplantation using a femtosecond laser. J Cataract Refract Surg. 2019; 45:261-6.

113 Dragnea DC, Birbal RS, HamDapena LI, Dapena I, Oellerich S, van Dijk K, et al. Bowman layer transplantation in the treatment of keratoconus. Eye Vis. 2018;5:24.
114 Dapena I, Musayeva A, Dragnea DC, Goenevld-van Beek E, Ni Dhubhghaill S, Parker JS, et al. Bowman layer onlay transplantation to manage herpes corneal scar. Cornea. 2020 Sep;39(9):1164-66.

115 Parker JS, Dockery PW, Parker JS, Dapena I, van Dijk K, Melles G. Bowman layer onlay graft for reducing fluctuation in visual acuity after previous radial keratotomy. Cornea. 2020 Oct;39(10):1303-6.

116 Jacob S, Patel SR, Agarwal A, Ramalingam A, Saijimol AI, Raj JM. Corneal allogenic intrastromal ring segments (CAIRS) combined with corneal cross-linking for keratoconus. J Refract Surg. 2018;34(5):296-303.

117 Parker JS, Dockery PW, Parker JS. Trypan blue assisted corneal allogenic intrastromal ring segment (CAIRS) implantation. J Cataract Refract Surg. Forthcoming 2020.

118 Dapena I, Parker JS, Melles GRJ. Potential benefits for modified corneal tissue grafts for keratoconus: Bowman layer 'inlay' and 'onlay' transplantation, and allogenic tissue ring segments. Curr Opin Ophthalmol. 2020; 31(4):276-83.

119 Van Dijk K, Parker JS, Baydoun L, Ilyas A, Dapena I, Groeneveld-van Beek EA, et al. Bowman layer transplantation: 5-year results. Graefes Arch Clin Exp Ophthalmol. 2018;256(6):1151-8.

120 Tong CM, Parker JS, Dockery PW, Birbal RS, Melles GRJ. Use of intraoperative anterior segment optical coherence tomography for Bowman layer transplantation. Acta Ophthalmol. 2019;97(7):e1031-2.

121 Parker JS, Huls F, Cooper E, Graves P, Groeneveld-van Beek EA, Lie J, et al. Technical feasibility of isolated Bowman layer graft preparation by femtosecond laser: a pilot study. Eur J Ophthalmol. 2017;27(6): 675-7.

122 Parker J, van Dijk K, Melles G. Updates in anterior lamellar keratoplasty: the state of the debates. Expert Rev Ophthalmol. 2016; 11(5):339-46.

123 Parker J, Parker J, Melles G. Descemet membrane endothelial keratoplasty: a review. US Ophthalmic Review. 2013;6:29-32.

124 Veldman PB, Dye PK, Holiman JD, Mayko ZM, Sáles CS, Straiko MD, et al. The S-stamp in Descemet membrane endothelial keratoplasty safely eliminates upside-down graft implantation. Ophthalmology. 2016;123(1): 161-4.

125 Birbal RS, Ni Dhubhghaill S, Bourgonje VJA, Hanko J, Ham L, Jager MJ, et al. Fiveyear graft survival and clinical outcomes of 500 consecutive cases after Descemet membrane endothelial keratoplasty. Cornea. 2020;39(3):290-7.

126 Birbal RS, Parker J, Dirisamer M, Janićijević A, Baydoun L, Dapena I, et al. Descemet membrane endothelial transfer: ultimate outcome. Cornea. 2018;37(2):141-4.

127 Parker J, Verdijk RM, Müller TM, Lavy I, Bruinsma M, Colby K, et al. Histopathology of failed Descemet membrane endothelial transfer. Eye Contact Lens. 2017;44(1):3614.

128 Oganesyan OG, Neroev VV, Grdikanyan AA, Getadaryan VR. Five keratoplasties from one donor cornea. Cornea. 2018;37(5): 667-71.

129 Garcerant D, Hirnschall N, Toalster N, Zhu M, Wen L, Moloney G. Descemet's stripping without endothelial keratoplasty. Curr Opin Ophthalmol. 2019;30(4):275-85.

130 Kinoshita S, Koizumi N, Ueno M, Okumura $\mathrm{N}$, Imai $\mathrm{K}$, Tanaka $\mathrm{H}$, et al. Injection of cultured cells with a ROCK inhibitor for bullous keratopathy. N Engl J Med. 2018; 378(11):995-1003.

131 Basak SK, Basak S, Gajendragadkar N, Ghatak M. Overall clinical outcomes of Descemet membrane endothelial keratoplasty in 600 consecutive eyes: a large retrospective case series. Indian J Ophthalmol. 2020;68(6): 1044-53.

132 Parker J, Dirisamer M, Naveiras M, Ham L, van der Wees J, Melles GR. Endothelial cell density after Descemet membrane endothelial keratoplasty: 1- to 4-year follow-up. Am J Ophthalmol. 2011;151(6):1107.

133 Miron A, Bruinsma M, Ham L, Schaal SC Baydoun L, Dapena I, et al. In vivo endothelial cell density decline in the early postoperative phase after Descemet membrane endothelial keratoplasty. Cornea. 2018;37(6): 673-7.

134 Quilendrino R, Höhn H, Tse WH, Chi H, Dapena I, Ham L, et al. Do we overestimate the endothelial cell "loss" after descemet membrane endothelial keratoplasty? Curr Eye Res. 2013;38(2):260-5.

135 Parker J, Dirisamer M, Naveiras M, Tse WH, van Dijk K, Frank LE, et al. Outcomes of Descemet membrane endothelial keratoplasty in phakic eyes. J Cataract Refract Surg. 2012;38(5):871-7.2012

136 Birbal RS, Baydoun L, Ham L, Miron A, van Dijk K, Dapena I, et al. Effect of surgical indication and preoperative lens status on Descemet membrane endothelial keratoplasty outcomes. Am J Ophthalmol. 2020; 212:79-87.

137 Godin MR, Boehlke CS, Kim T, Gupta PK. Influence of lens status on outcomes of Descemet membrane endothelial keratoplasty. Cornea. 2019;38(4):409-12.

138 Siggel R, Heindl LM, Cursiefen C. Descemet membrane endothelial keratoplasty (DMEK) in phakic eye with shallow anterior chamber. Graefes Arch Clin Exp Ophthalmol. 2015;253(5):817-9.

139 Gundlach E, Maier AK, Tsangaridou MA, Riechardt AI, Brockmann T, Bertelmann E, et al. DMEK in phakic eyes: targeted therapy or highway to cataract surgery? Graefes Arch Clin Exp Ophthalmol. 2015;253(6): 909-14.

140 Reddy J, Hammersmith K, Nagra P, Rapuano $\mathrm{C}$. The role of penetrating keratoplasty in the era of selective lamellar keratoplasty. Int Ophthalmol Clin. 2013;53(2):12. 
141 Wisse RP, van den Hoven CM, Van der Lelij A. Does lamellar surgery for keratoconus experience the popularity it deserves? Acta Ophthalmol. 2014;92(5):473-7.

142 Williams KA, Ash JK, Pararajasegaram P, Harris S, Coster DJ. Long-term outcome after corneal transplantation. Visual result and patient perception of success. Ophthalmology. 1991;98(5):651-7.

143 Uiters E, van den Borne B, van der Horst FG, Völker-Dieben HJ. Patient satisfaction after corneal transplantation. Cornea. 2001;20(7): 687-94.
144 Limaiem R, Chebil A, Baba A, Ben Youssef N, Mghaieth F, El Matri L. Pediatric penetrating keratoplasty: indications and outcomes. Transplant Proc. 2011;43(2):649-51.

145 Ganekal S, Gangangouda C, Dorairaj S, Jhanji V. Early outcomes of primary pediatric keratoplasty in patients with acquired, atraumatic corneal pathology. J AAPOS. 2011;15(4):353-5.

146 Cullen JF, Butler HG. Mongolism (down's syndrome) and keratoconus. Br J Ophthalmol. 1963;47:321-30.
147 Giedd KK, Mannis MJ, Mitchell GL, Zadnik K. Personality in keratoconus in a sample of patients derived from the internet. Cornea. 2005;24(3):301-7.

148 Martin TP, Reed JW, Legault C, Oberfeld SM, Jacoby BG, Yu DD, et al. Cataract formation and cataract extraction after penetrating keratoplasty. Ophthalmology. 1994; 101(1):113-9.

149 Nagra PK, Rapuano CJ, Laibson PL, Kunimoto DY, Kay M, Cohen EJ. Cataract extraction following penetrating keratoplasty. Cornea. 2004;23(4):377-9. 